\title{
¿Statistical and Empirical Relationships between Tornado Intensity and Both Topography and Land Cover Using Rapid-Scan Radar Observations and a GIS
}

\author{
JANA B. Houser, NATHANiEl McGinnis, ${ }^{a}$ AND Kelly M. Butler ${ }^{\mathrm{b}}$ \\ Department of Geography, Ohio University, Athens, Ohio
}

HOWARD B. BLUESTEIN

School of Meteorology, University of Oklahoma, Norman, Oklahoma

JEFFREY C. SNYDER

NOAA/OAR/National Severe Storms Laboratory, Norman, Oklahoma

MiCHAEL M. FRENCH

School of Marine and Atmospheric Sciences, Stony Brook University, State University of New York, Stony Brook, New York

(Manuscript received 23 December 2019, in final form 15 June 2020)

\begin{abstract}
This study presents an investigation into relationships among topographic elevation, surface land cover, and tornado intensity using rapid scan, mobile Doppler radar observations of four tornadoes from the U.S. Central Plains. High spatiotemporal resolution observations of tornadic vortex signatures from the radar's lowest elevation angle data (in most cases ranging from $\sim 100$ to $350 \mathrm{~m}$ above ground level) are coupled with digital elevation model (DEM) and 2011 National Land Cover Database (NLCD) data using a geographic information system (GIS). The relationships between 1) tornado intensity and topographic elevation or surface roughness and 2) changes in tornado intensity and changes in topographic elevation or surface roughness are investigated qualitatively, and statistical relationships are quantified and analyzed using a bootstrap permutation method for individual case studies and all cases collectively. Results suggest that there are statistically significant relationships for individual cases, but the relationships defy generalization and are different on a case-by-case basis, which may imply that they are coincidental, indicating a null correlation.
\end{abstract}

\section{Introduction}

Considerable time and effort have been devoted to investigating the storm-scale and vortex dynamics associated with tornadoes, particularly as they form (e.g., Brandes 1978; Leslie and Smith 1978; Lemon and Doswell 1979;

¿ Denotes content that is immediately available upon publication as open access.

\footnotetext{
${ }^{\text {a }}$ Current affiliation: National Weather Service, Wilmington, Ohio.

${ }^{\mathrm{b}}$ Current affiliation: National Weather Service, Wichita, Kansas.
}

Corresponding author: Dr. Jana Houser, houserj@ohio.edu
Wilczak et al. 1992; Wicker and Wilhelmson 1995; Dowell and Bluestein 1997; Bluestein et al. 2003; Markowski et al. 2003; Wurman et al. 2007a; Davies-Jones 2008; Kosiba et al. 2013; French et al. 2013; Markowski and Richardson 2014; Houser et al. 2015; Coffer et al. 2017; Markowski et al. 2018; Bluestein et al. 2019). Numerical modeling and observational studies frequently focus on storm-scale features and processes associated with the generation of the vorticity that feeds the low-level mesocyclone and tornado (e.g., Klemp and Rotunno 1983; Brandes 1984; Rotunno and Klemp 1985; Wicker and Wilhelmson 1995; Markowski et al. 2003; Wurman et al. 2007b; Marquis et al. 2012; Kosiba et al. 2013; Naylor and Gilmore 2014; Mashiko 2016; Orf 2017; Houston 2017; Davies-Jones 2017). Other studies have determined that low-level 
(and perhaps deeper) tornado structure, intensity, and evolution are a function of the thermodynamic and kinematic characteristics within the boundary layer, where the effects of friction directly impact the wind field (e.g., Davies-Jones 1973; Lewellen et al. 1997; Howells et al. 1988; Lewellen et al. 2000; Nolan and Farrell 1999; Davies-Jones et al. 2001; Kosiba and Wurman 2013; Wurman et al. 2013; Rotunno 2013; Rotunno et al. 2016; Nolan et al. 2017).

Early numerical and laboratory studies (e.g., Ward 1972; Lewellen 1976; Davies-Jones 1973) found that, to a large extent, the structure and intensity of a tornado is governed by the swirl ratio, $S$ (Davies-Jones 1973; Rotunno 1979):

$$
S=\frac{R \Gamma_{R}}{2 Q},
$$

where $R=$ the updraft radius, $\Gamma_{R}$ is proportional to the circulation at radius $R$, and $Q$ is proportional to the volume flow rate through the vortex. The swirl ratio can be interpreted as the ratio between azimuthal flow at the edge of the vortex to the vortex's updraft speed; or, similarly, a measure of rotation versus convergence into the vortex, and is governed by the characteristics of the inflow air. When ambient vorticity is large, the numerator will increase, and when the convergence into the vortex is large, the denominator will increase. The structure of the vortex is related to $S$ (Ward 1972; Davies-Jones 1986; Lewellen et al. 2000). A smaller $S$ will result in a single-cell vortex, dominated by a central updraft and a convergent boundary layer flow field. As $S$ increases, a central downdraft develops along the vortex axis, surrounded by a more turbulent, wider flow field. Increasing $S$ further will result in the vortex transitioning to a two-celled structure with the central downdraft permeating to the surface, and eventually to a multiple-vortex structure (for a visual, refer to Davies-Jones et al. 2001). Thus, the degree to which boundary layer flow is dominated by vorticity versus convergence will determine whether a tornado will tend to have multiple vortices or a single, laminar vortex, which will affect the intensity of the tornado.

It has been found that the height at which maximum winds occur within a tornado can be quite low $(<10 \mathrm{~m})$, and the depth of inflow into tornadoes is very shallow ( $\leq 10-20 \mathrm{~m}$ AGL) (Bluestein et al. 2007; Kosiba and Wurman 2013; Wurman et al. 2013). Considering the near-surface location of the height of maximum winds as well as the sensitivity of tornado intensity and structure to a very shallow surface-based inflow layer, it is intuitive that the characteristics of the physical ground surface underlying the inflow and over which the tornado is translating will likely impact tornado structure, intensity, and evolution. For example, topography and surface roughness will affect boundary layer flow through the magnitude of friction present. Consequently, the amount of convergence into the vortex will also be affected by these factors, and therefore $S$ will be affected as well. Thus, a vortex encountering varying surface roughness or topography may potentially undergo a change in structure and/or intensity as a result of variations in $S$.

However, little attention has been devoted to studying interactions between the tornado and the ground. Some early laboratory studies of vortex dynamics investigated such interactions in wind chambers. Results do indeed suggest that properties of the ground over which the vortex is occurring and translating impact the vortex's structure and intensity (e.g., Dessens 1972; Leslie 1977; Smith and Leslie 1979; Rotunno 1979; Lewellen 1993; Davies-Jones 2015; Wienhoff et al. 2020, manuscript submitted to Mon. Wea. Rev.). Furthermore, topography and the frictional properties of the land cover have been proven to affect the vortex's intensity and physical structure (Lewellen 2012, 2014), and they may influence its genesis (Kellner and Niyogi 2014; Schenkman et al. 2014; Roberts et al. 2016; Lyza and Knupp 2018; Hua and Chavas 2019). Recent numerical simulations have provided additional support of these relationships (e.g., Coffer and Parker 2017; Dahl et al. 2017; Fiedler 2017). As such, it is important to consider the impacts that terrain and land cover (which is directly related to surface roughness) will have on a tornado.

One of the motivating hypotheses for this work is that the vertical vorticity of a tornado is a function of the depth of the vortex and the net convergence or divergence acting upon the vortex. This assumption is driven by the relationships illustrated through the following equations:

$$
\begin{aligned}
& \frac{D}{D t}\left(\frac{\zeta+f}{h}\right)=0, \\
& \frac{d \zeta}{d t}=-\zeta\left(\nabla \cdot \mathbf{V}_{h}\right),
\end{aligned}
$$

where (2) is the equation for conservation of absolute vorticity for a barotropic, incompressible, and frictionless atmosphere, and (3) is a simplified form of the vertical vorticity equation for a column of air with purely rotational flow (i.e., there is no radial inflow). Here, $\zeta$ is the vertical component of relative vorticity, $f$ is the Coriolis parameter, $h$ is the depth of the column, and $\nabla \cdot \mathbf{V}_{h}$ is the divergence of the horizontal wind $\left(\mathbf{V}_{h}\right)$. According to these equations, a change in the vertical depth of the vortex affects the relative vorticity of the vortex, assuming $f$ is constant (which is appropriate for 
time and space scales of tornadoes), and changes in vertical vorticity are proportional to horizontal convergence or divergence acting upon the column. Since terrain affects $h$, and friction affects convergence into the vortex, these equations provide a mathematical basis for the analyses provided in this study.

Although most tornadoes do not have a physical surface bounding them aloft, and the assumptions about the atmosphere mentioned above are clearly violated for tornadoes, it is possible that tornadoes may, to some degree, still behave in a manner consistent with (2) and (3). If these relationships are indeed valid, even in part, it would be expected that as a tornado crosses a ridge, hill, valley, or similar topographic feature, cyclonic vorticity should decrease upon ascent due to vertical shrinking ( $h$ decreases) and net horizontal mass divergence $\left(\nabla \cdot \mathbf{V}_{h}>0\right)$, and it should increase upon descent due to vertical stretching ( $h$ increases) and net horizontal mass convergence $\left(\nabla \cdot \mathbf{V}_{h}<0\right)$. It should be noted, however, that the relative height of the topographic feature compared to the depth of the vortex is likely important: this effect should be more pronounced for higher relief topography and shallower vortices.

There is numerical and observational evidence that tornado intensity and sometimes formation or dissipation can be affected by terrain features (e.g., Fujita 1989; Evans and Johns 1996; Bluestein 2000; Dunn and Vasiloff 2001; Homar 2003; LaPenta et al. 2005; Bosart et al. 2006; Lewellen and Lewellen 2007; Lewellen 2012; Coleman 2010; Karstens et al. 2013; Tang et al. 2016; Lyza and Knupp 2018). However, in other situations, the presence of high-relief topography appears to have inhibited a vortex from continuing its forward motion, causing it to decay (e.g., Hardy 1971; Golden 1968). Furthermore, it is likely that complex terrain will alter the structure of storm-scale cold pools and/or the direction and speed of inflow (Bosart et al. 2006; LaPenta et al. 2005; Lyza and Knupp 2018), which will affect a supercell's ability to produce a tornado.

Relationships between friction/surface roughness or land surface type and tornado structure, intensity and genesis have also been identified using observations and numerical simulations (e.g., Dessens 1972; Smith and Leslie 1979; Diamond and Wilkins 1984; Rotunno 2013; Lewellen 2014; Schenkman et al. 2014; Kellner and Niyogi 2014; Roberts et al. 2016; Fiedler 2017; Frazier et al. 2019; Markert et al. 2019). Early studies that specifically investigated the role of friction with respect to tornado evolution utilized laboratory vortex chambers. Dessens (1972) analyzed a laboratory model of a tornadolike vortex and concluded that surface friction weakened the tornado. However, Diamond and Wilkins (1984) later refuted the results from Dessens (1972) and further concluded that the vortex's radius of maximum winds decreased when friction was added to the lower surface boundary in their simulation. Additionally, they noted that differential friction could result in asymmetrical inflow, which could alter the structure and dynamics of the tornado. Smith and Leslie (1979) also concluded that adding surface friction resulted in stronger vortices than those occurring without friction.

Some of the first numerical modeling studies to investigate the role friction plays in vortex dynamics were conducted by Fiedler (1994) and Fiedler and Trapp (1995). These studies collectively concluded that introducing friction can have marked impacts on tornadogenesis and vortex intensity. A more recent numerical modeling study by Lewellen (2014) confirmed that increasing friction at the surface reduces the angular momentum of the inflow, noting that in multiple instances, a vortex strengthened after passing over roughness elements. Recent work by Fiedler (2017) explored differences in tornado structure that occur as a direct response of varying the surface drag coefficient. Additionally, both Schenkman et al. (2014) and Roberts et al. (2016) concluded that surface friction played an important role in the generation of vertical vorticity that contributed to tornadogenesis in simulated supercells, though the contribution of frictional vorticity to the development of near-ground rotation in the presence of cold pools is unclear (Markowski 2016).

Despite the foundation provided by early laboratory simulations and recent numerical simulations, to date, there have been no peer-reviewed observational studies quantitatively investigating how the intensity of a tornado may be affected by topography or surface friction. Although some work has been devoted to examining the relationships between tornado behavior (genesis/decay, structure, path, and intensity) and surface topography, many of these studies have been idealized in some manner, and those that are observational [except Lyza and Knupp (2018) and Hua and Chavas (2019)] only analyzed a small number of cases or a singular event. Multiple observational studies have investigated ties between tornadogenesis and surface roughness $^{1}$ (e.g., Lamb 1957; Hardy 1971; Fujita 1973; Snider 1977; Elsom and Meaden 1982; Kellner and Niyogi 2014) but most of these studies suffer from spatiotemporal deficiencies, and, furthermore, their results have also been conflicting. Several studies have analyzed the effects that certain ground cover characteristics have on the tornadic debris signature (e.g., Bodine et a. 2013, 2014; Atkins et al. 2014; Wakimoto et al. 2016, 2018) but these

\footnotetext{
${ }^{1}$ The terms surface roughness and friction are used interchangeably throughout this manuscript.
} 
studies have not explicitly linked the intensity of the tornado to the land cover type.

This study is the first of its kind to examine high spatiotemporal radar observations of tornadoes with respect to the ground over which they are occurring or translating. Rapid scan, mobile radar data from four tornadoes that occurred in the U.S. plains region are analyzed. While this area of the country generally does not have particularly high topographic relief, Lyza and Knupp (2014) determined that topographic elevation changes as small as $20 \mathrm{~m}$ had an impact on tornado intensity in their study, and Karstens et al. (2013) found similarly that elevation changes as small as $30 \mathrm{~m}$ were impactful. Such conditions are commonly found throughout the central plains and in the study domain (Figs. 1a,c).

This study specifically addresses the following questions through a combined analysis of rapid-scan mobile radar observations, and topographic elevation and land cover type within a GIS:

1) Is a tornado's intensity ${ }^{2}$ partially a function of its local relative surface elevation? Specifically, will a tornado be more intense when in contact with a surface that has a lower elevation than its surroundings?

2) Does a tornado's intensity change if it moves up or down a slope?

3) Is a tornado's intensity partially a function of the surface roughness over which it is occurring or moving? Specifically, will a tornado be more intense when in contact with land covers having a relatively high surface roughness?

4) Does a tornado's intensity change as it moves from land covers characterized by lower surface roughness to land covers with higher surface roughness, and vice versa?

These questions are addressed by statistically evaluating the complex relationships between tornado intensity and topographic elevation/surface roughness in an effort to provide preliminary insight into the role the lower physical boundary plays in tornado evolution.

\section{Data}

\section{a. Mobile, rapid scan radar data}

Mobile radar data were collected by the Mobile Weather Radar-2005 X-band, Phased Array [MWR-05XP Bluestein et al. (2010)] and Rapid X-band Polarimetric [RaXPol; Pazmany et al. (2013)] radars. The MWR-05XP

\footnotetext{
${ }^{2}$ For the purposes of this study, "intensity" is estimated by the magnitude of the tornado's Doppler velocity couplet velocity differential (see section 3a).
}

is a mobile, phased array, $3-\mathrm{cm}$ wavelength radar that is mechanically steered in azimuth and electronically steered in elevation. The instrument simultaneously collects data over 10 or more elevation angles which, combined with the high-speed pedestal, dramatically reduces the volumetric data acquisition time compared to traditional mobile and fixed-site radars. Depending on the volume coverage pattern (sector size, number of elevation angles desired, etc.), a full volume scan can be completed in 6-24s.

$\mathrm{RaXPol}$ is a mobile, $3-\mathrm{cm}$ wavelength, polarimetric radar with a traditional parabolic antenna. It utilizes frequency hopping (Doviak and Zrnić 1993, p. 180), in which the transmitted frequency is changed after each pulse pair, reducing the time required to obtain quasiindependent sampling. It is mechanically steered in both azimuth and elevation, but the use of a high-speed pedestal capable of a $180^{\circ} \mathrm{s}^{-1}$ azimuthal rotation rate results in $360^{\circ}$ plan-position indicator scans in just $2 \mathrm{~s}$. RaXPol can therefore complete a 10 elevation angle volume scan in $\sim 22 \mathrm{~s}$ (when including slight overhead associated with elevation angle changes).

Five rapid-scan case studies from four tornadoes were included in the analyses described herein (Table 1, Fig. 1): 1) the Goshen County, Wyoming, EF-2 tornado from 5 June 2009 (MWR-05XP) (Kosiba et al. 2013; French et al. 2014); 2) the Lookeba, Oklahoma, EF-2 tornado from 24 May 2011 (RaXPol) (Houser et al. 2015); 3) the El Reno, Oklahoma, EF-5 tornado from 24 May 2011 (Houser et al. 2015; French et al. 2015) (sampled at separate times by MWR-05XP and RaXPol); and 4) the Edmond-Carney, Oklahoma, EF-3 tornado from 19 May 2013 (RaXPol) (Wienhoff 2016). Update times ranged from 2 to $52 \mathrm{~s}$, and distance to the tornado varied from $\sim 3$ to $30 \mathrm{~km}$ but was generally between 5 and $20 \mathrm{~km}$. For more details about the cases, see Table 1.

The rapid scan data input into the statistical algorithms used for the El Reno RaXPol case were downscaled to $20 \mathrm{~s}$ by eliminating data between $20 \mathrm{~s}$ intervals, in an effort to ensure the similarity of sampling intervals between the different cases. Only data from the lowest elevation angle available were used in all cases, corresponding to beam heights between $\sim 100$ and $350 \mathrm{~m}$ above ground level (AGL) for most cases, although for some times in certain cases the beam height was as low as $70 \mathrm{~m}$ or as high as $1600 \mathrm{~m}$ (Table 1 ).

We used only data that were representative of the mature phase of the tornado (i.e., data from 3 to $5 \mathrm{~min}$ after genesis and 3-5 min before decay were not used) because storm-scale processes likely dominated the trend in $\Delta V_{\max }$ during formation/dissipation. The precise time frame ( 3 versus $5 \mathrm{~min}$ ) for data omission was dependent upon the tornado and was selected based upon when the original intensification or weakening trends in $\Delta V_{\max }$ 

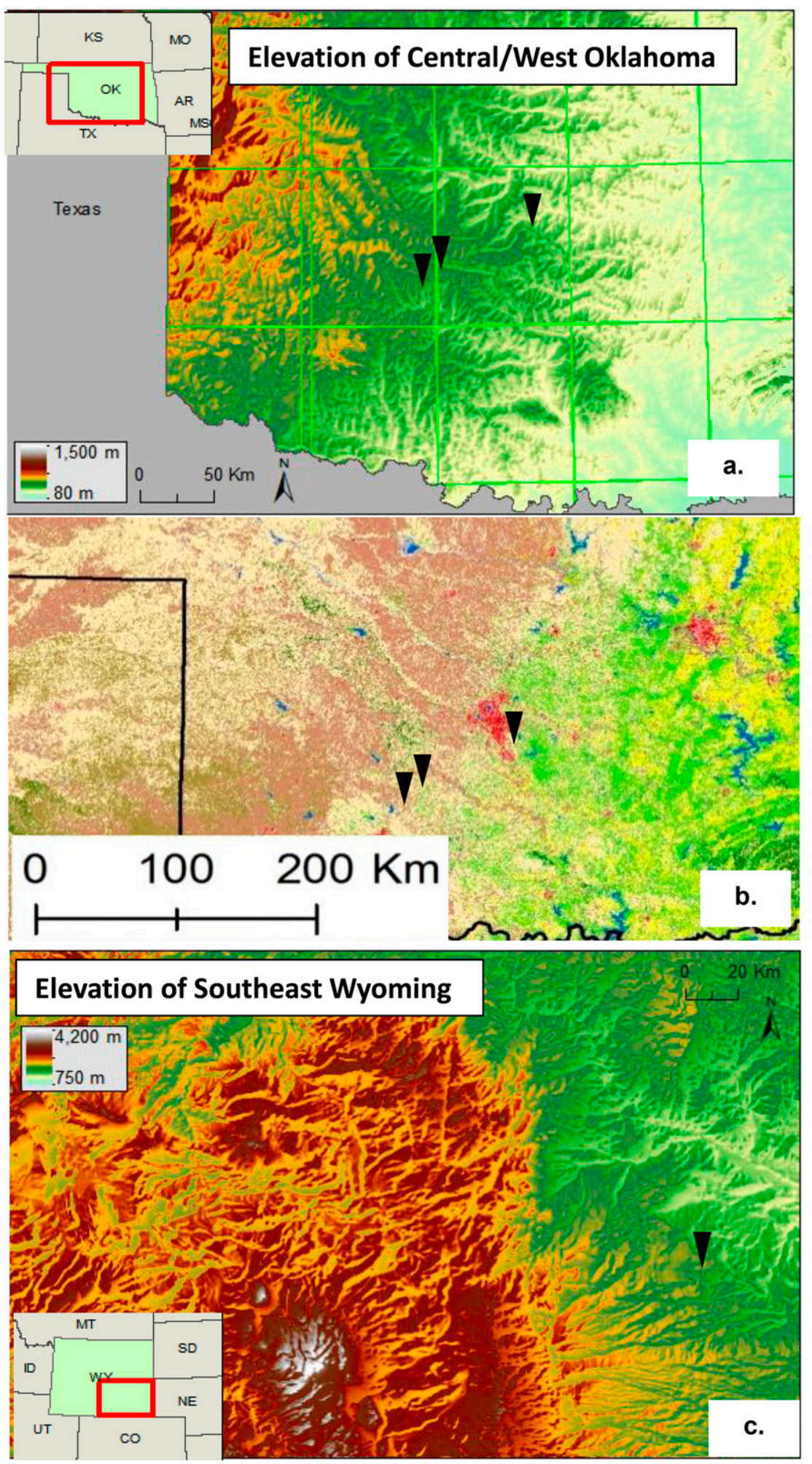

Copen Water

$\square$ Perennial Ice/Snow

$\square$ Developed Open Space

$\square$ Developed Low Intensity

-Developed Med Intensity

Developed High Intensity

$\square$ Barren Land

$\square$ Deciduous Forest

Evergreen Forest

$\square$ Mixed Forest

Shrub/Scrub

$\square$ Grassland/Herbaceous

$\square$ Pasture/Hay

$\square$ Cultivated Crops

$\square$ Woody Wetlands

FIG. 1. Geographic characteristics of the mobile radar datasets. (a) DEM data for central Oklahoma (light green lines are DEM panels), (b) land-cover data for Oklahoma, and (c) DEM data for SE Wyoming. Land cover for WY not shown because there was little variation (primarily grassland/herbaceous with small areas of cultivated crops). Tornado locations are indicated by the black triangles. 
TABLE 1. Summary of rapid scan, mobile radar case studies. Data collection time is given in UTC for the time frame over which data are available. Scan interval is the time required to complete one full volume scan in seconds. Number of volumes is the number of volume scans completed that are contributing to the analyses, or effectively, the sample size of each case study. Beam height is the range of the radar beam above ground level over the course of the deployment $(\mathrm{m})$. Gate spacing is the radial sampling interval $(\mathrm{m})$. Azimuthal crosssectional range is the cross-beam distance associated with the $1.5^{\circ}\left(1^{\circ}\right)$ sampling interval for the MWR (RaXPol) spanning the distance range between the radar and the TVS. Elevation range is the range in topographic elevations (m) above mean sea level (MSL) over the duration data are available obtained from the DEM data. Mean (median) elevation is the statistical mean (median) of the topographic elevation (m MSL, from DEM data) over the duration for which observations were collected for each case; $Z_{L}$ range is the range of average roughness length values $(\mathrm{m})$ within the surface area of the tornadic circulation over the duration of the deployment, and $\Delta V_{\text {max }}$ range is the range of tornado intensities represented by $V_{\max \text { out }}-V_{\max \text { in }}$ in $\mathrm{m} \mathrm{s}^{-1}$. EF scale is the NWS determined damage rating. Tornadogenesis is the official NWS time of tornado formation (UTC). Dissipation is the official NWS time of tornado decay (UTC).

\begin{tabular}{|c|c|c|c|c|}
\hline Case & Goshen & Lookeba & El Reno & Edmond-Carney \\
\hline Date & 5 Jun 2009 & 24 May 2011 & 24 May 2011 & 19 May 2013 \\
\hline Collection time (UTC) & 2200:00-2220:34 & 2037:18-2046:20 & 2051:22-2149:43 (intermittent) & 2149:17-2206:36 \\
\hline Instrument & MWR & RaXPol & MWR and RaXPol & RaXPol \\
\hline Volume scan interval (s) & $\sim 6$ & $\sim 17$ & From 2 to $\sim 17$ & $\sim 52$ \\
\hline No. of volumes & 189 & 34 & 258 (RaXPol), 81 (MWR) & 22 \\
\hline Beam height (m AGL) & $157-259$ & $942-1624$ & 71-321 (RaXPol), 237-505 (MWR) & $89-255$ \\
\hline Gate spacing $(\mathrm{m})$ & 75 & 70 & 75 (MWR), 15 (RaX) & 45 \\
\hline Azimuthal cross-sectional range $(\mathrm{m})$ & $144-445$ & $218-366$ & $52-523$ & $157-279$ \\
\hline Topographic elevation range (m MSL) & $1475-1540$ & $423-488$ & $408-497$ & $266-328$ \\
\hline $\begin{array}{l}\text { Mean (median) topographic elevation } \\
\text { (m MSL) }\end{array}$ & $1519(1523)$ & $445(455)$ & 439 (454) (RaX), 393 (393) (MWR) & $295(295)$ \\
\hline Distance to TVS (km) & $5.5-17$ & $12.5-21$ & $3-30$ & $9-16$ \\
\hline$Z_{L}$ range $(\mathrm{m})$ & $0.08-0.1$ & $0.05-1.3$ & $0.03-0.43$ & $0.13-0.87$ \\
\hline$\Delta V_{\max }$ range $\left(\mathrm{m} \mathrm{s}^{-1}\right)$ & $43-110$ & $50-111$ & $58-192$ & $67-145$ \\
\hline EF scale & 2 & 2 & 5 & 3 \\
\hline Tornadogenesis (UTC) & 2152 & 2031 & 2050 & 2141 \\
\hline Dissipation (UTC) & 2231 & 2046 & 2235 & 2224 \\
\hline
\end{tabular}

were obvious (not shown). For the $2011 \mathrm{El} \mathrm{Reno}{ }^{3}$ tornado dataset, MWR-05XP and RaXPol both collected data on the tornado, but they did so at different times. RaXPol collected data from genesis ( 2051 UTC) to 2116 UTC (e.g., Houser et al. 2015), and the MWR-05XP collected data from a different location between $\sim 2133$ and 2203 UTC (e.g., French et al. 2014). Owing to differences in the distance to the tornado, the azimuthal resolutions of the radars (the half-power beam widths are $1^{\circ}$ and $1.8^{\circ}$ for RaXPol and the MWR-05XP, respectively), and the physical surfaces over which the tornado was traversing at the different times, these two datasets, although collected for the same tornado, are analyzed separately. Assumptions and limitations about the data collected are given in the appendix.

\section{b. GIS data}

Data for topography and land-cover type were analyzed using ESRI ArcMap. The data were visualized using the geographic coordinate system North American 1983 (GCS_NA_1983) datum and the projected coordinate system used was the North American equidistant

\footnotetext{
${ }^{3}$ Note: This is not the same tornado that impacted El Reno, OK, on 31 May 2013.
}

conic. Topographic elevation data were retrieved from the digital elevation model (DEM) dataset, which has data available every $30 \mathrm{~m}$. Land-cover data were obtained from the National Land Cover Dataset (NLCD; Homer et al. 2015); these data are also available every $30 \mathrm{~m}$. Thus, both the DEM and NLCD data have gridbox areas of $90 \mathrm{~m}^{2}$. These data are of finer resolution than the radar data, which have range gate-azimuth areas ranging from 780 (RaXPol El Reno) to $33375 \mathrm{~m}^{2}$ (Goshen). Considering the tornadoes in this study had distances between wind maxes ranging from $\sim 200 \mathrm{~m}$ to $1.2 \mathrm{~km}$ (not shown), the resolution of the DEM and NLCD data is more than adequate for finding elevations and surface roughness associated with the vortex and actually introduces the opposite problem of how to best represent the elevation and surface roughness over the relatively large area where the tornado traverses over the ground. In this study, an area average surface roughness is used, but elevations are taken as point measurements at the center of the vortex (refer to section $3 \mathrm{~b}$ for details.)

The NLCD dataset classifies land cover into one of 16 qualitative categories (Table 2). To conduct a statistical analysis, these categories had to be assigned quantitative values. We chose to use the surface roughness length values for March, April, and May (MAM), specified in the Environmental Protection Agency's AIRSURFACE 
TABLE 2. Surface roughness length values, ordered from smallest to largest, as specified by the EPA's AERSURFACE user's guide (EPA 2008) for the classes given by the NLCD. The provided values are valid for March, April, and May, to correspond to the times of the radar observations used in this study.

\begin{tabular}{lc}
\hline \multicolumn{1}{c}{ Land cover } & Roughness length $(\mathrm{m})$ \\
\hline Open water & 0.001 \\
Perennial ice/snow & 0.002 \\
Developed open space & 0.015 \\
Pasture/hay & 0.03 \\
Cultivated crops & 0.03 \\
Barren land & 0.05 \\
Grassland/herbaceous & 0.05 \\
Emergent herbaceous wetlands & 0.2 \\
Shrub/scrub & 0.3 \\
Developed low intensity & 0.52 \\
Woody wetlands & 0.7 \\
Developed med intensity & 0.83 \\
Developed high intensity & 1 \\
Deciduous forest & 1 \\
Mixed forest & 1.1 \\
Evergreen forest & 1.3 \\
\hline
\end{tabular}

User's Guide (EPA 2008), which were calculated specifically for the NLCD's qualitative categories (Table 2). Values for individual months are not available. MAM was chosen over JJA because wheat crops are often harvested in June, causing differences in the surface roughness lengths between the two time frames. The calendar dates of events only vary by 17 days, and leafout on trees and shrubs has already occurred by May so it is unlikely that using the same roughness values for all cases will introduce significant error.

\section{Analysis methods}

\section{a. Radar data analysis}

Prior to analysis, radial velocity data from the radar's lowest elevation angle available in each dataset (Table 1) were manually unfolded in order to correct for velocity aliasing. Tornado intensity at beam height was then estimated by calculating the difference between the maximum inbound and outbound radial velocities $\left(\Delta V_{\max }\right)$ within the tornadic vortex signature $\left(\mathrm{TVS}^{4}\right)$ (identified

\footnotetext{
${ }^{4}$ Technically, the term "tornadic vortex signature" refers to the Doppler velocity couplet associated with a tornado when the beamwidth is too large to fully resolve the tornadic circulation, whereas a "tornado signature" (TS) refers to the couplet when the beam is sufficiently small and the tornado is fully resolved. In these datasets, there are times when the tornado is fully resolved and times when it is not. To keep terminology consistent and to avoid confusion, we choose to refer to all Doppler velocity signatures associated with a tornado as a "TVS," even though sometimes it is technically a TS.
}

manually) such that $\Delta V_{\max }=V_{\max \text { inbound }}-V_{\max \text { outbound }}$. No TVS magnitude threshold was imposed because data contributing to this study came from tornadoes that were confirmed through NWS damage surveys, storm report genesis and decay times from the SPC, and visual observations by the radar operating crews. Thus, there was no ambiguity about whether or not radar-observed rotation was associated with a tornado. We also considered analyzing statistical relationships using the distance between the $V_{\max }$ inbound and $V_{\max }$ outbound data points to provide further physical insight into changes on the tornado's radius of maximum wind. However, it was determined that this distance varied too significantly from sweep to sweep due to nonmeteorological factors (viz., inadequate spatial sampling of finite data points with a three-dimensional radar beam) to provide meaningful analysis (not shown).

Upon calculating $\Delta V_{\max }$, the latitude and longitude of the TVS center were recorded. Additionally, in order to approximate the surface area over which tornado-strength winds were occurring, which is relevant for surface roughness calculations, the distances between the TVS center and either the $+35 \mathrm{~m} \mathrm{~s}^{-1}$ and/or the $-35 \mathrm{~m} \mathrm{~s}^{-1}$ isodops, were measured. This wind speed was chosen because it corresponds to the middle of the estimated wind speed interval for an EF0 rated tornado (Wind Science and Engineering Center 2004) after it was first determined that using the lowest value of an EF0 included areas that were obviously outside of the tornado. More information about the use of this information is given in the next section.

\section{b. GIS analysis}

After the radar-based data were retrieved, the latitude and longitude of the TVS center and the approximate radius of tornado-strength winds were imported into ESRI ArcMap for GIS analysis. The topographic elevation above mean sea level (MSL) at the location (lat-lon) of the TVS center was acquired from the DEM data. Because the base-state ground elevation MSL varied from case to case (e.g., the average elevation of the Wyoming case was $1519 \mathrm{~m}$ MSL while that of the Edmond-Carney case was $295 \mathrm{~m}$ MSL), elevation deviations were calculated. This was done separately for each case by calculating the mean topographic elevation (MSL) over all the observations in the case, then subtracting the mean from the topographic elevation at each individual TVS center location. This process allows for a meaningful intercomparison of relative high and low topographic elevations between cases. Without using mean elevations, the datasets would be biased by the regional context of elevation above sea level, precluding a meaningful intercase comparison. The deviation from the statistical median (rather than mean) was 
also investigated, but it was determined that there were no significant differences in the results when the median was used (not shown).

Obtaining surface roughness data was not straightforward. The quantitative values associated with land cover tended to be noisier over the ground area affected by the tornado than the elevation data owing to the discrete nature of the initially categorical data. Therefore, using a point value for surface roughness at the TVS center was not always representative of the broader land cover nearby. Instead, an average surface roughness value was calculated from all the roughness length values associated with the various land cover types contained within a circle approximately centered on the middle of the TVS (Fig. 2). The area enclosed by the circle was assumed to be the most impactful to the tornado as it interacted with the ground. The circle's diameter was determined by one of two ways: 1 ) For cases in which only one side of the TVS had Doppler velocities that exceeded $35 \mathrm{~m} \mathrm{~s}^{-1}$, the diameter was equal to two times the distance between the TVS center and the outer edge of the +35 or $-35 \mathrm{~m} \mathrm{~s}^{-1}$ isodop within the TVS (whichever had a magnitude exceeding $35 \mathrm{~m} \mathrm{~s}^{-1}$ ) (Fig. 2a). 2) In cases for which both inbound and outbound velocities exceeded $35 \mathrm{~m} \mathrm{~s}^{-1}$, the circle's diameter was equal to the distance between the outer edges of the +35 and $-35 \mathrm{~m} \mathrm{~s}^{-1}$ isodops straddling the TVS (Fig. 2b). The final dataset was a table of observations that linked a TVS's center location (latitude and longitude) and $\Delta V_{\max }$ with the topographic elevation, the deviation elevation (from the mean), the average surface roughness of the $\sim 35 \mathrm{~m} \mathrm{~s}^{-1}$ circle, and the changes in $\Delta V_{\max }$, topographic elevation, and average surface roughness that occurred from one scan to the next.

\section{c. Statistical analysis}

The underlying motivation of this study is whether we can statistically discern if TVS intensity is different when tornadoes are 1) at higher or lower topographic elevations relative to the general surroundings and 2) over land cover with higher or lower surface roughness values. We also seek to examine if changes in either land cover or elevation are associated with changes in tornado intensity. Datasets for individual mobile radar cases (with case sample sizes ranging from 22 to 258 TVS observations) were first analyzed independently. Then, the data were subsequently aggregated and examined as a group in an effort to identify statistical trends that could be generalized across cases. Unfortunately, Doppler velocity data were not normally distributed, and data from the same tornado event were not independent of each other. Consecutive velocity observations were typically within close spatial and temporal
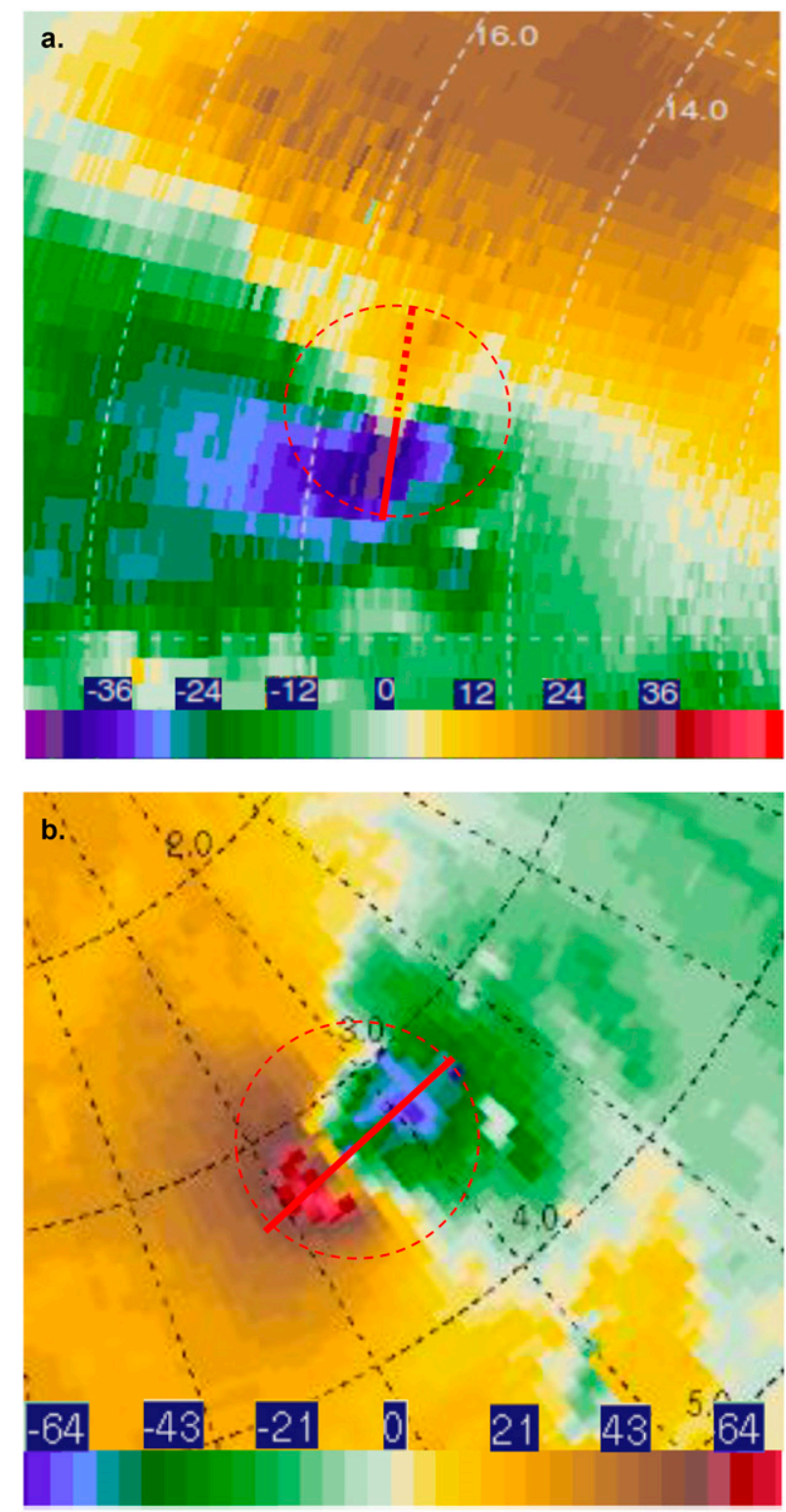

FIG. 2. Doppler velocity images of a TVS from (a) 2149:26 UTC 19 May 2013 (the Shawnee, OK, tornado) and (b) 2058:03 UTC 24 May 2011. In (a), the solid red line indicates the distance from the center of the tornado to the $-35 \mathrm{~m} \mathrm{~s}^{-1}$ isodop, while the dotted red line indicates the radius of the same distance but on the outbound velocity side of the TVS, where Doppler velocities were less than $35 \mathrm{~m} \mathrm{~s}^{-1}$. In (b), the solid red line indicates the distance between the +35 and $-35 \mathrm{~ms}^{-1}$ isodop, passing through the center of the TVS. The interior area of the dashed circle in both panels depicts the region over which the surface roughness average was calculated. Note the differences in the color bar values.

proximity and therefore were correlated both spatially and temporally. Because of these restrictions, traditional parametric statistics were not used. Rather, a bootstrapping permutation method was employed 
that makes minimal assumptions about the underlying data distribution (Efron 1982).

The process of bootstrapping assumes that the data sample is representative of the population and recreates a large number of synthetic "replicates" or resamples. The replicates are of the same size as the original sample but are generated by randomly extracting data points from the original sample, with replacement allowed (i.e., the same $\Delta V_{\max }$ observation can be incorporated into one replicate multiple times). All original observations within a dataset have the same probability $(1 / n$, where $n$ is the sample size) of being selected in each new resampled replicate. Each replicate dataset has its own statistics (e.g., mean, variance, etc.), and, by repeating the resampling process many $(1000+)$ times, a distribution of these statistics is created, which can be used to determine confidence intervals of the statistic being analyzed (Fig. 3).

For the purposes of this study, we compared the distribution of the means of $\Delta V_{\text {max }}$ for two different groups to evaluate the relationship(s) in question. The observed datasets of interest were divided into two groups of separate $\Delta V_{\text {max }}$ values that were associated with a userspecified geographic condition. Two ranges (a range of high values and a range of low values) of topographic elevation or surface roughness were selected, and all $\Delta V_{\max }$ measurements that were associated with the elevations or surface roughness values contained within those ranges were placed into two different groups as well. For example, to test the hypothesis that "tornadoes are more intense when they travel over higher elevations (relative to the case mean)," all $\Delta V_{\max }$ observations that occurred in topography with a deviation elevation exceeding $0 \mathrm{~m}$ comprised the first group, and all $\Delta V_{\max }$ observations occurring where deviation elevations were less than or equal to $0 \mathrm{~m}$ comprised the second group. Similarly, the $\Delta V_{\max }$ values associated with the upper and lower quartile of topographic elevation observations were bootstrapped independently, and the distribution of their means were compared. To address relationships between tornado intensity and surface roughness, the first group was composed of all $\Delta V_{\max }$ observations associated with upper quartile average surface roughness lengths while the second group contained all $\Delta V_{\text {max }}$ 's associated with the lower quartile average surface roughness lengths.

The observations from both groups were passed to the bootstrapping algorithm in MATLAB 2016B to generate resampled replicates for statistical comparison. The means of 1000 bootstrapped replicates were calculated for the upper and lower groups, individually, and histograms for each group's resampled means were generated. A difference in means test was used to compare the means from both groups. If less than $5 \%$ of the area of the joint distribution of both histograms overlapped, the two groups were considered to be representative of different populations, and, therefore, their means were considered to be statistically different (Fig. 3c). This result implies, but does not by itself prove, that the samples came from two different populations and by extension, that TVS characteristics were different between the two groups being tested.

Not only may the actual values of the topographic elevation and surface roughness data affect $\Delta V_{\max }$, but changes in elevation or surface roughness may be associated with changes in $\Delta V_{\max }$. To address this, differences in elevation or surface roughness from scan to scan were computed as were changes in $\Delta V_{\text {max }}$ between two consecutive volume scans as follows:

$$
\begin{aligned}
d(\mathrm{el})= & \text { topographic elevation at } \operatorname{scan} n, \\
& \text { topographic elevation at } \operatorname{scan} n-1, \\
d\left(Z_{L}\right)= & \text { average surface roughness at } \operatorname{scan} n, \\
& \text { average surface roughness at } \operatorname{scan} n-1, \\
d \Delta V_{\max }= & \Delta V_{\max } \text { at } \operatorname{scan} n, \quad \Delta V_{\max } \text { at } \operatorname{scan} n-1 .
\end{aligned}
$$

Each of these datasets was divided into 2 groups, similarly to what was done earlier, with each group bootstrapped independently, and the difference in means test described above was used.

\section{Results and analysis}

As mentioned earlier, four tornadoes (five cases) were analyzed. The Lookeba, El Reno, and Edmond-Carney tornadoes were evaluated with respect to both topography and surface roughness changes, while only topography was analyzed for the Goshen County tornado because the land cover characterization did not change enough to warrant any possible correlation with tornado intensity; the average roughness length only varied by $\sim 0.02 \mathrm{~m}$ for this case (Table 2 ).

Although there are a wide variety of storm-scale processes that can affect the intensity of a tornado (and drive changes in that intensity), storm-scale processes were not examined in the context of changes in $\Delta V_{\text {max }}$. We acknowledge that this is a significant limitation of this study. However, we are interested in examining links between tornado intensity and the land over which the tornado was moving, and we are assessing whether these trends are discernable at times, even if the associations or relationships are not statistically significant. In the context of an observational study, it is impossible to determine the extent to which storm-scale features might be contributing to the strength of the 
a.

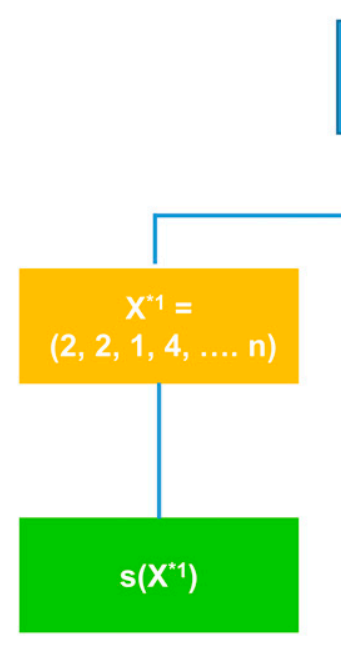

Block Diagram of the Bootstrapping Process

\section{Observed Data \\ Sample}

b.

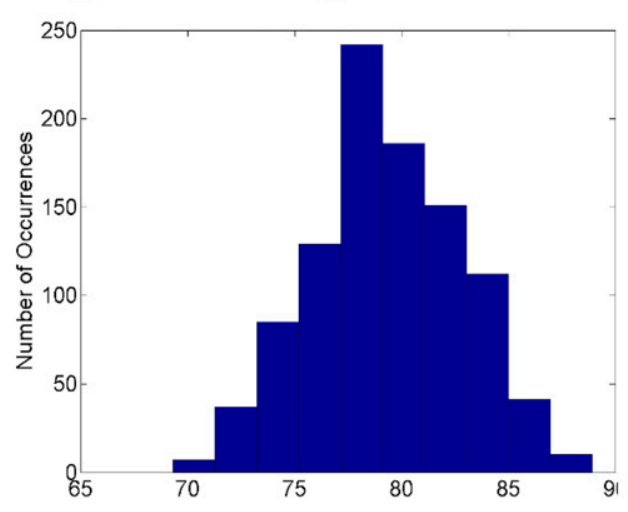

\section{c. Joint Histograms of Mean Velocities}

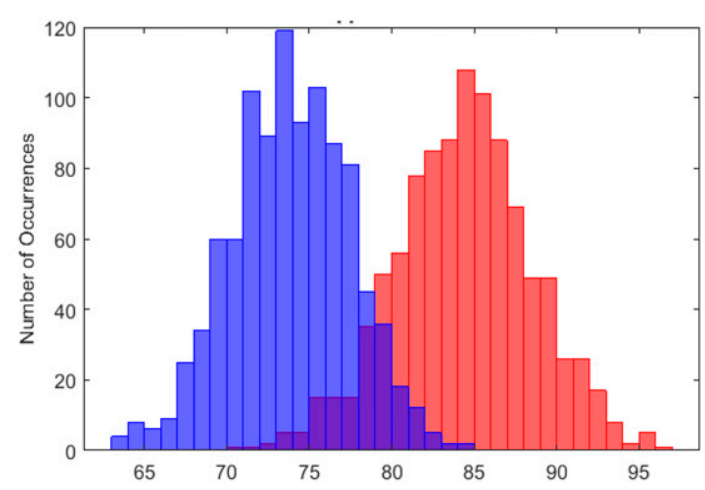

FIG. 3. Schematic illustration of the bootstrapping process and statistical analysis. (a) Block diagram illustrating bootstrapping; $X$ is the original dataset containing all $(n)$ observations of velocity data: $1,2,3,4, \ldots, n$. The various $X^{*}$ s are the resampled replicates generated from the original data in $X$, with the same sample size $n$; $S$ can be any statistic (e.g., mean, standard deviation, etc.) generated for each of the individual $X^{*}$ replicates. Adapted from Efron and Tibshirani (1994). (b) An example histogram of statistic $S$. The $x$ axis is the value of the statistic (here, mean velocity) for all replicates and the $y$ axis is the number of occurrences of that mean. The width of the bar represents $1 \mathrm{~m} \mathrm{~s}^{-1}$. (c) An example of joint histograms from the two different sampled groups. Blue = group 1, red $=$ group 2 . The overlap is given in purple. If the purple area contains $<5 \%$ of the total area of the two histograms, the groups have statistically significantly different means.

tornado versus the extent to which ground characteristics affect the intensity and intensity changes. Furthermore, ground characteristics might themselves impact stormscale processes (e.g., Bosart et al. 2006; Prociv 2012; Lyza and Knupp 2018). Thus, one of the biggest drawbacks of an observational study such as this is that various contributors to tornado intensity are inextricably linked and cannot be isolated.

Nevertheless, we proceed to investigate only the links between ground elevation and surface roughness with tornado intensity in an effort to advance our understanding between these factors. The results of these five cases are broken down into multiple subsections: the first addresses direct correlations with topographic elevation, the second examines changes in elevation, the third addresses correlations with land cover, and the fourth examines correlations with changes in land cover.

\section{a. Intensity and topographic elevation}

A geographic overview of the four tornadoes being analyzed with respect to topographic elevation and land-cover type is given in Fig. 1. For all cases, elevation 


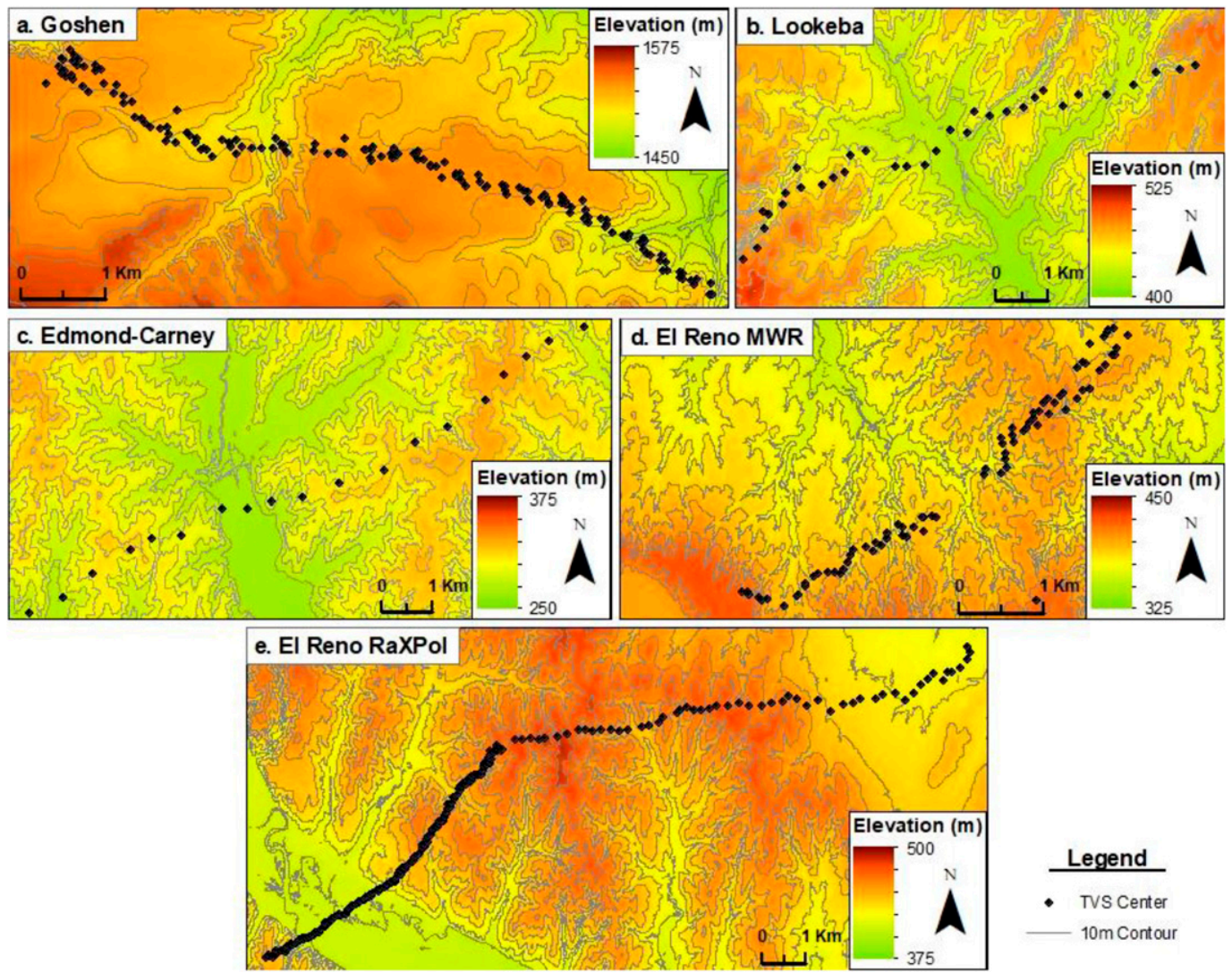

FIG. 4. DEM data for each of the observed cases. Starting values for contours are variable, but each color increment corresponds to an equal topographic elevation change. Black dots represent lat-lon locations of the tornado: (a) Goshen County, 2200-2216 UTC 10 Jun 2009; (b) Lookeba, 2037-2046 UTC 24 May 2011; (c) Edmond-Carney, 2149-2206 UTC 19 May 2013; (d) El Reno, 2142-2149 UTC 24 May 2011, MWR-05XP; and (e) El Reno, 2102-2116 UTC 24 May 2011, RaXPol.

changes of at least $60 \mathrm{~m}$ occur over the data collection interval (Table 1). Most elevation changes occur as the tornadoes move over river valleys or drainage ravines (Fig. 4). Qualitatively, the observed $\Delta V_{\max }$ data correlate with the elevation, roughly, for some cases (Fig. 5), but for the case of Lookeba (Fig. 5b), the correlation appears rather robust. Both the Lookeba and Goshen tornadoes (Figs. 5a,b) were generally stronger at lower topographic elevations and weaker at higher elevations. However, there also were times during which this trend did not hold (e.g., the Goshen tornado weakened slightly while going downhill between about 2202 and 2203 UTC. Kosiba et al. (2013) also noted weakening around this time (their Fig. 6), although the exact time weakening began was not precisely the same as ours for two of their three radars, likely owing to differences in sampling).

Relationships between topographic elevation and $\Delta V_{\max }$ from the El Reno and Edmond-Carney tornadoes are less obvious. There is some evidence in the El Reno
RaXPol dataset that the tornado strengthened when descending $\sim 30 \mathrm{~m}$ into a river valley at $\sim 2056$ UTC. However, there is no indication that the tornado subsequently weakened when ascending the opposite bank. Then, near the end of RaXPol's data collection period, the TVS weakened considerably (by $>50 \mathrm{~m} \mathrm{~s}^{-1}$ ) while the tornado was on relatively flat terrain. This period of weakening was mentioned in Houser et al. (2016) in association with debris fallout from the tornadic debris signature, but no cause for this weakening was discussed. About 20 min later, when the MWR-05XP radar was observing the tornado, there was a gradual intensification trend that also did not appear to be correlated with the changes in topography, though there was some evidence of a relationship between lower topography and stronger $\Delta V_{\max }$ during the first $\sim 10 \mathrm{~min}$ of data collection. The Edmond-Carney tornado tended to increase in intensity steadily throughout the 15 -min data acquisition timeframe, irrespective of the trends in underlying topography. 

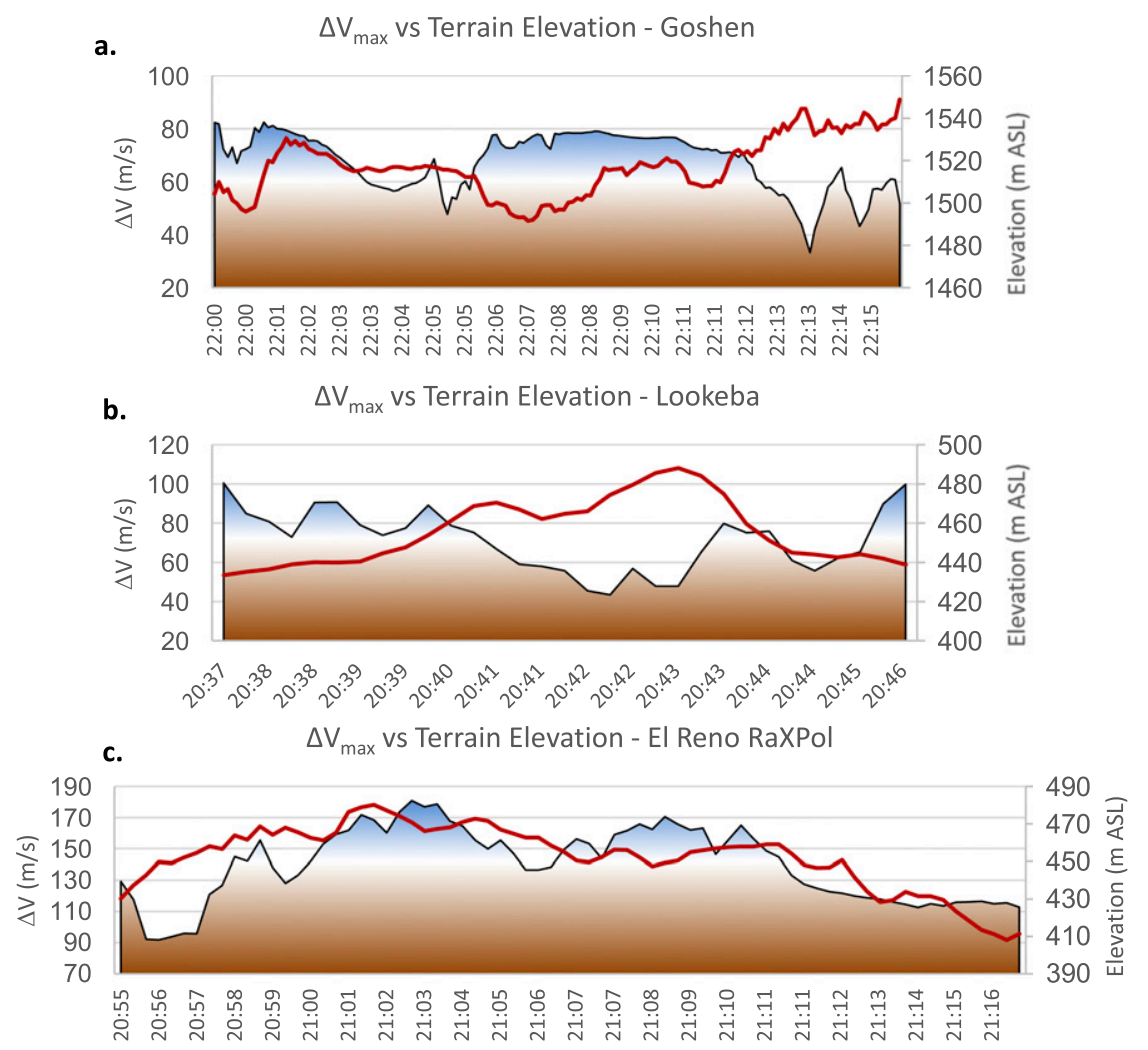

d.

$\Delta \mathrm{V}_{\max }$ vs Terrain Elevation - El Reno MWR
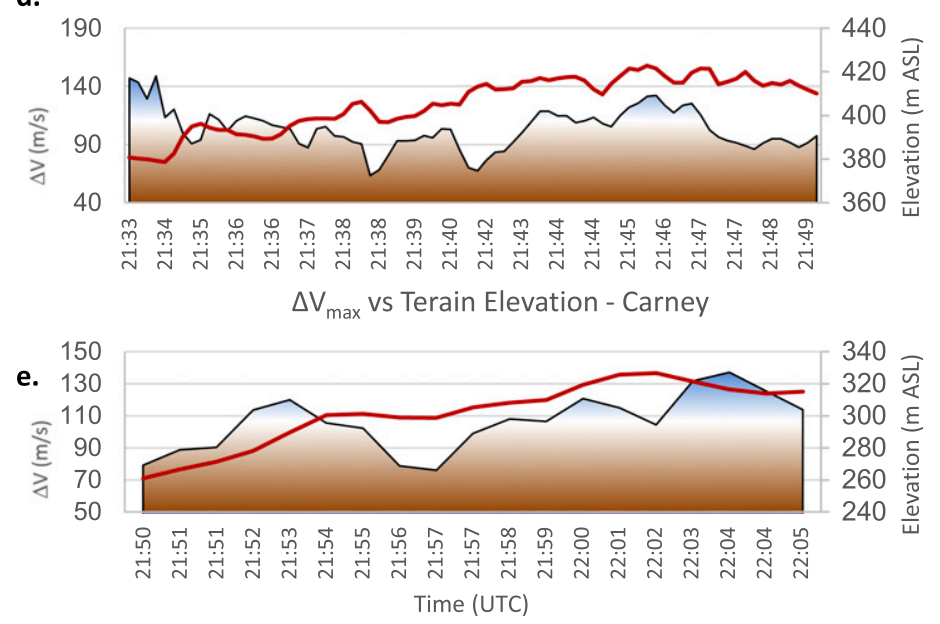

FIG. 5. Time series ( $x$ axis) of TVS intensity ( $\mathrm{m} \mathrm{s}^{-1}$; left $y$ axis), as determined by the $\Delta V_{\max }$ measurement (red line), and topographic elevation (filled below the black line) retrieved from the DEMs (m above sea level; right $y$ axis) for (a) Lookeba, (b) Goshen, (c) El Reno (RaXPol dataset), (d) El Reno (MWR-05XP dataset), and (e) Edmond-Carney, tornadoes. (Note, the height of the Doppler velocity measurement is NOT indicated. Refer to Table 1 for the range of heights AGL for each deployment.)

For statistical testing, the data for each case were broken down as discussed in section $3 b$. Histograms from the bootstrapped $\Delta V_{\max }$ values associated with positive and negative topographic elevation deviations are given in Fig. 6. It is evident from this figure that there are distinct distributions of the means between the two groups for nearly all of the cases. For the Goshen County (Fig. 6a) and Lookeba (Fig. 6b) tornadoes, there is a statistically significant correlation between topographic elevation and $\Delta V_{\max }$ such that 
a. Goshen $\Delta \mathbf{V}_{\max }$ Bootstrapped Mean vs. EL

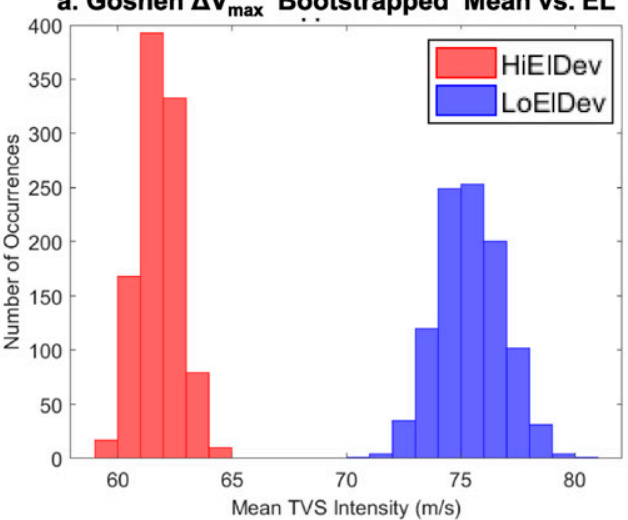

b. Lookeba $\Delta \mathbf{V}_{\max }$ Bootstrapped Mean vs. EL

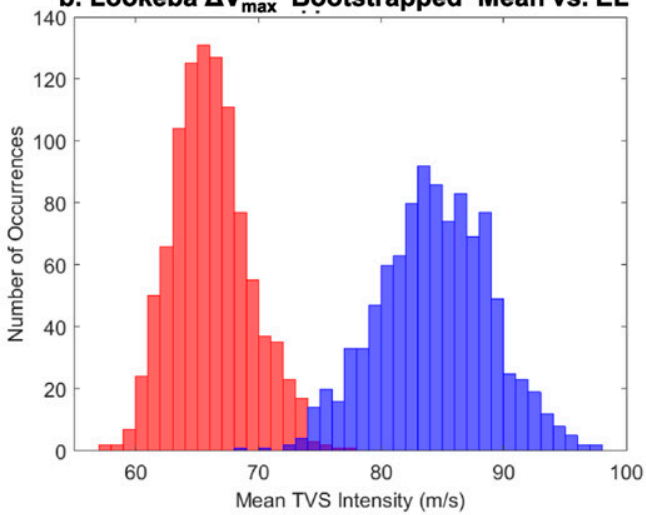

c. El Reno RaXPol $\Delta \mathbf{V}_{\max }$ Bootstrapped Mean vs. EL

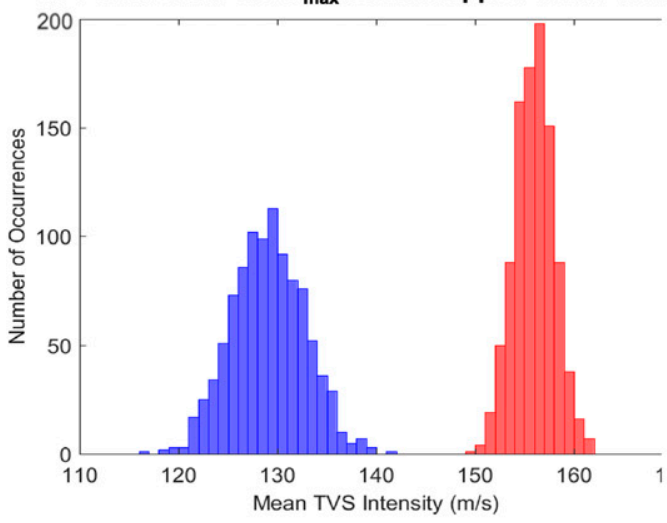

d. El Reno MWR $\Delta \mathbf{V}_{\max }$ Bootstrapped Mean vs. EL

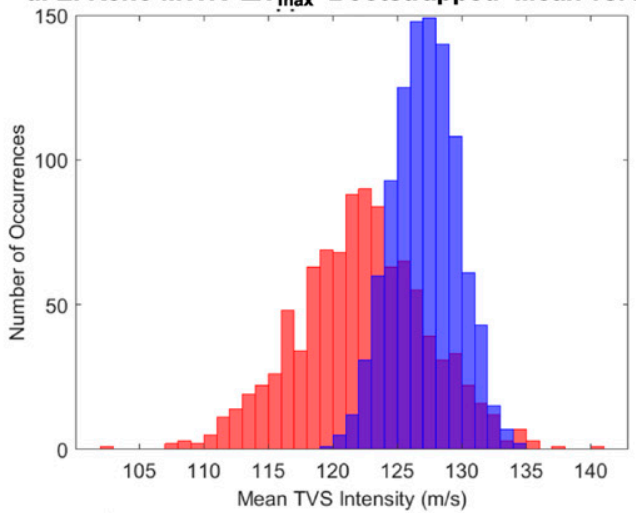

Carney $\Delta \mathbf{V}_{\max }$ Bootstrapped Mean vs. EL

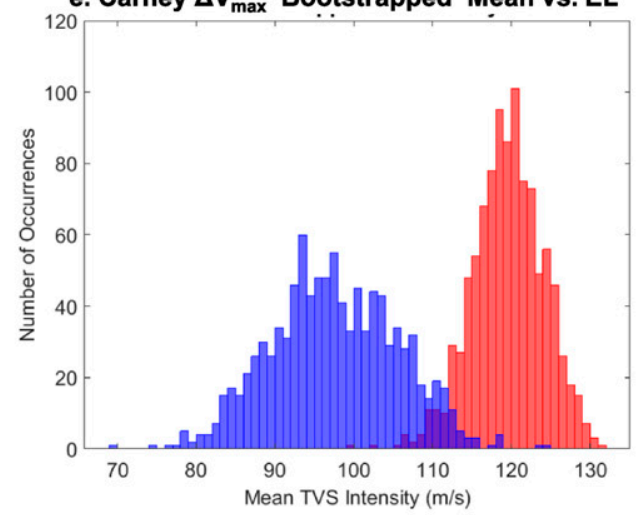

f. All Cases Combined

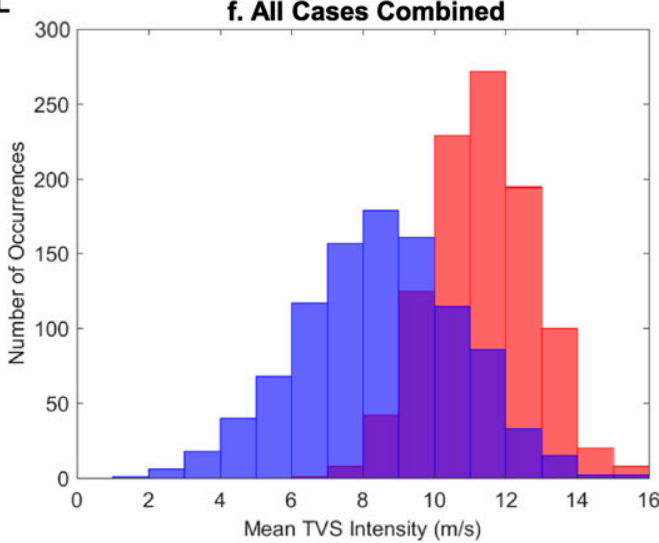

FIG. 6. Histograms of bootstrapped means of TVS intensity ( $\Delta V_{\max }, x$ axis) vs frequency of that mean occurring over the 1000 replicates ( $y$ axis) separating subsamples for positive topographic elevation deviations (red) and negative elevation deviations (blue). Bins are $1 \mathrm{~m} \mathrm{~s}^{-1}$ wide. (a) Goshen County, (b) Lookeba, (c) El Reno (RaXPol dataset), (d) El Reno (MWR-05XP dataset), (e) Edmond-Carney, and (f) all cases combined. The $x$ axis in (f) is the deviation of the TVS from the mean rather than the values of the TVS since the mean TVSs for each case were different.

higher topography (red histogram) is associated with weaker TVSs. In the former case, there is no overlap between the two bootstrapped samples and for the latter case, less than $1 \%$ of the area of both histograms overlaps. A similar trend can be gleaned from the El Reno MWR-05XP dataset, although there is too much overlap between the two bootstrapped datasets to imply that they are statistically different. One potentially impactful factor to the El Reno MWR-05XP dataset is that there was minimal change in topographic elevation over the course of tornado data collection ( $<25 \mathrm{~m}$ for any given topographic feature). 
In comparison, the El Reno RaXPol and the EdmondCarney datasets both show the opposite tendency-higher topography is associated with stronger TVSs. These bootstrapped samples are also significantly different; the El Reno RaXPol dataset has no overlap and the Carney dataset has less than $5 \%$ overlap. It is seen in Figs. $5 \mathrm{c}$ and $5 \mathrm{e}$ that the strongest (weakest) velocities do indeed occur over the highest (lowest) topographic elevations. For the El Reno case specifically, observations associated with most of the lower topographic data were collected either $\sim 5 \mathrm{~min}$ after tornadogenesis as the tornado was initially intensifying, or within $\sim 5 \mathrm{~min}$ of the end of the deployment, during which time significant structural changes were occurring associated with the weakening vortex (Houser et al. 2016). For the Edmond-Carney tornado, there is a general increase in intensity with time that is coupled with the general increase in topographic elevation. The $40 \mathrm{~m}$ elevation decrease between 2153 and 2157 UTC does not noticeably affect the intensity of the tornado. For both cases, the trends in $\Delta V_{\max }$ do not appear to be well matched with individual topographic peaks or valleys, raising the question of whether or not this correlation truly represents the physical processes we desired to test. Without strong evidence demonstrating links between topographic features and velocity, it is entirely possible that storm-scale processes overwhelm any effects related to topography in these cases.

When the data from all the cases are combined into one large sample, the deviation of $\Delta V_{\max }$ from the individual case means is considered. Deviations greater than zero represent TVSs stronger than each case's average, and those less than zero represent weaker TVSs. This is done in order to enable a comparison between cases where the TVS was weaker in general with cases where the TVS was stronger. The TVS data were not Gaussian distributed. As a result, deviations from the mean were not centered around $0 \mathrm{~m} \mathrm{~s}^{-1}$. Instead, there were more positive deviations than negative deviations. When all observations from the five cases were considered in aggregate, there was a signal that TVSs were stronger over higher topography relative to each case's average elevation (Fig. 6f). This result should be viewed with some caution, however. Considering the different results between different cases, a generalizable trend cannot be discerned.

The second technique employed for statistical evaluation was to isolate only the original TVS observations that were associated with the upper and lower quartiles of topographic elevation data. This method enables a comparison of the more extreme elevations, neglecting the data that are close to the average elevation value for each dataset. Results from this procedure mirror that from the original technique that included all elevation data for each case (Fig. 7). A notable difference is that when upper and lower quartile data from all cases combined together were compared (Fig. 7f), there was no signal for a difference in means between the upper quartile (higher) elevation data (green histogram) and lower quartile (lower) elevation data (purple histogram).

In summary, the trends between $\Delta V_{\max }$ and topographic elevation for the Goshen County and Lookeba cases are consistent with the hypothesized link between stronger (weaker) intensity and higher (lower) elevation via conservation of vorticity arguments, both looking at the raw data in Fig. 5, as well as the bootstrapped histograms in Figs. 6 and 7. These results suggest that for these cases, when the tornadoes were at lower elevations, they were perhaps stronger owing to stretching of the vortex over a greater vertical distance. Alternatively, when the tornadoes were at higher elevations, they were weaker, perhaps as a result of vertical compression of the vortex. In contrast, the results from the El Reno and Carney datasets suggest the opposite correlation that is also statistically significant. When taken in aggregate, the statistical results from the various cases do not suggest a clear relationship between topographic elevation and TVS intensity, likely owing to limitations previously identified in sections 2 and 3 and discussed in the appendixes.

\section{b. Intensity and topographic elevation changes}

The previous section focused on relationships between high and low topographic elevations and tornado intensity. However, the relationships between changes of topographic elevation from scan to scan and changes in the $\Delta V_{\max }$ values from scan to scan were also investigated (Fig. 8). None of the cases have statistically significant differences, as all histograms have substantial overlap between instances in which the elevation increases with time (red bars) and those in which elevation decreases with time (blue bars). Despite a lack of statistical significance, all cases except the Edmond-Carney case depict a tendency for positive (negative) elevation changes to be associated with decreases (increases) in $\Delta V_{\text {max }}$. This link is best seen in the Lookeba and Goshen cases, even though the results are not statistically significant when looking at the entire datasets. For Goshen, there is a sudden weakening in the TVS at 2205 UTC, as the tornado ascends $\sim 40 \mathrm{~m}$. It increases gradually in intensity as it crosses the plateau it just ascended, and then strengthens again notably around 2212 UTC as it descends $\sim 60 \mathrm{~m}$ down the other side. In the case of Lookeba, the tornado begins intensifying around 2039 UTC, as it descends a small hill, and it continues to strengthen as it 
a. Goshen Bootstrapped Mean $\Delta \mathrm{V}_{\max }$ Quarts $\mathrm{El}$

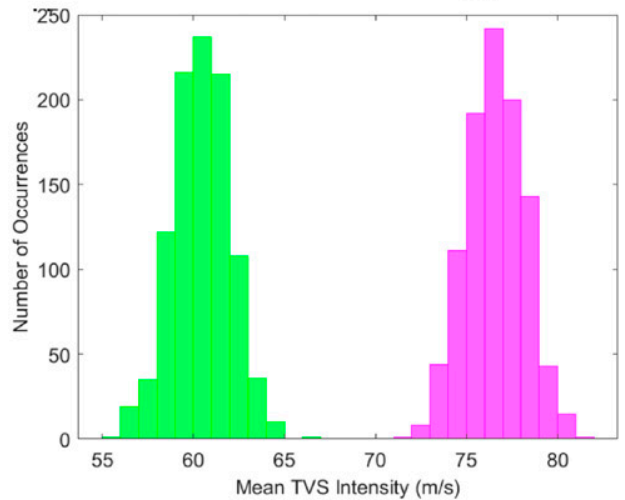

b. Lookeba Bootstrapped Mean $\Delta \mathrm{V}_{\max }$ Quarts $\mathrm{El}$

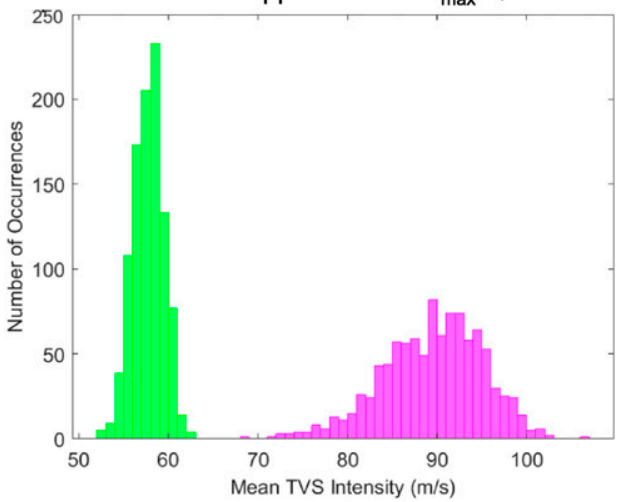

c. El Reno RaX Bootstrapped Mean $\Delta \mathrm{V}_{\max }$ Quarts El

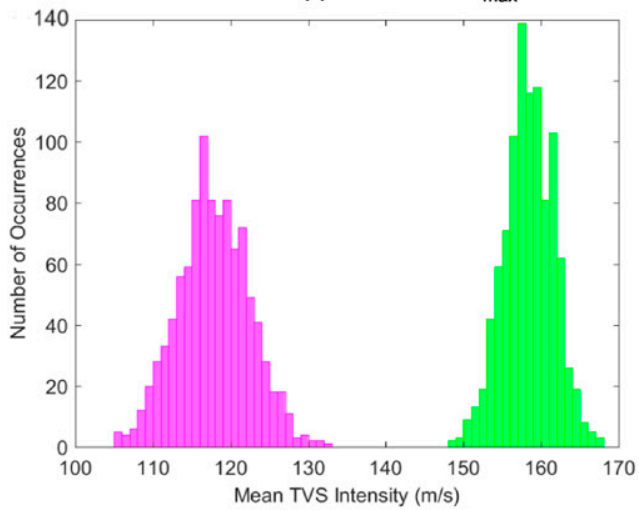

d. El Reno MWR Bootstrapped Mean $\Delta \mathrm{V}_{\max }$ Quarts El
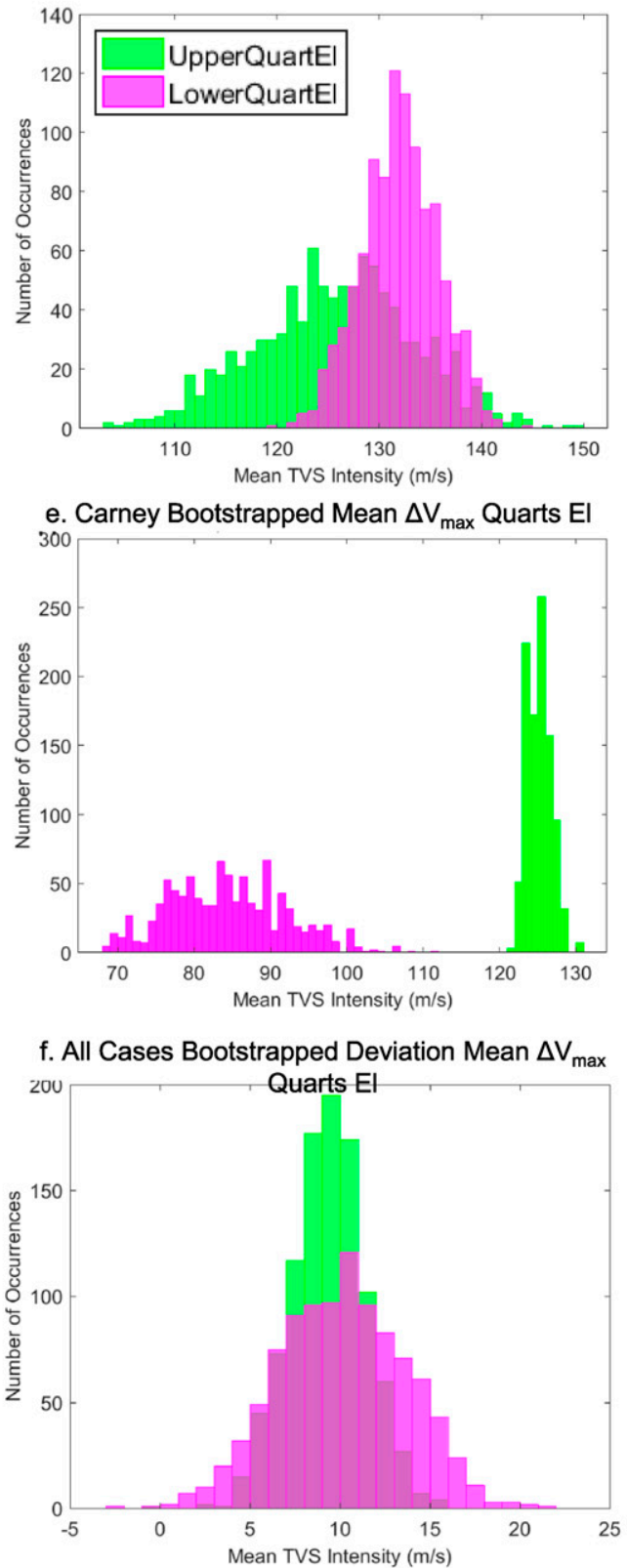

FIG. 7. As in Fig. 6, but for bootstrapped histograms using the upper and lower quartiles of topographic elevation and their associated $\Delta V_{\max } \mathrm{s}$. Green $=\Delta V_{\max } \mathrm{s}$ associated with elevations from the upper quartile (i.e., higher topography). Purple $=\Delta V_{\max }$ associated with lower quartile elevations (i.e., lower topography).

descends down the larger river valley, although there are a few elevation and velocity changes that do not follow this trend within that time interval. The tornado then weakened as it ascended the adjacent ridge exiting the river valley. This result can be interpreted to mean that the tornadoes weakened as they ascended topographic features and strengthened when they descended such features, as hypothesized via the conservation of vorticity
[Eq. (1)]. However, caution should again be exercised as these relationships do not always hold for each topographic feature. Other cases do not show clear links. Furthermore, when all the cases are combined together, the result is ambiguous, although there is a weak signal for decreasing (increasing) intensity with increasing (decreasing) topographic elevation. The upper and lower quartile data (not shown) offered very similar results. 
a. Goshen $\Delta \mathrm{V}_{\max }$ Change with El Change

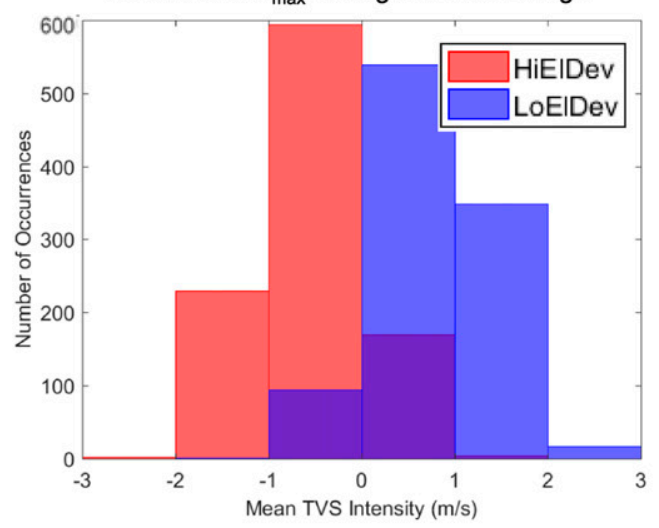

b. Lookeba $\Delta \mathrm{V}_{\max }$ Change with El Change

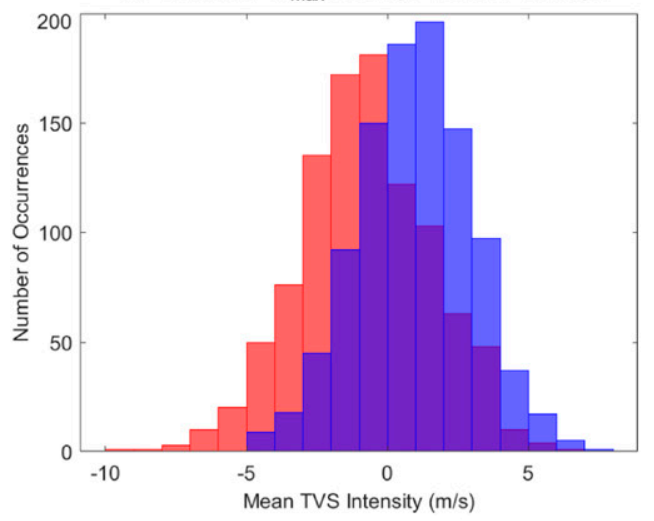

c. El Reno RaXPol $\Delta \mathrm{V}_{\max }$ Change with El Change

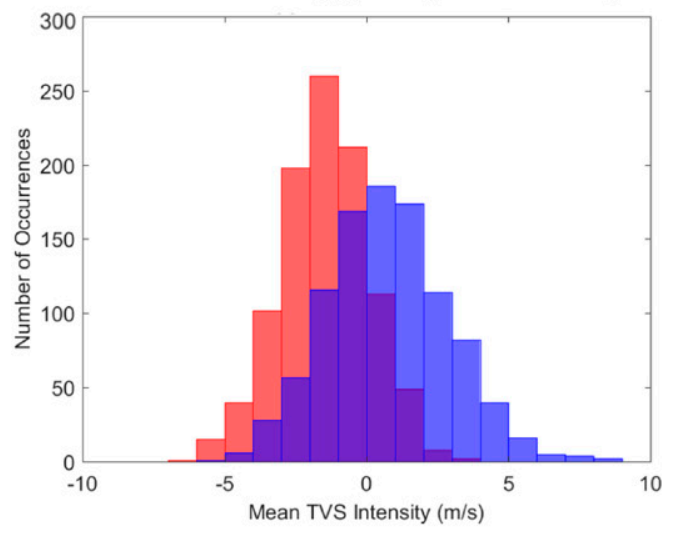

d. El Reno MWR-05XP $\Delta V_{\max }$ Change with El Change
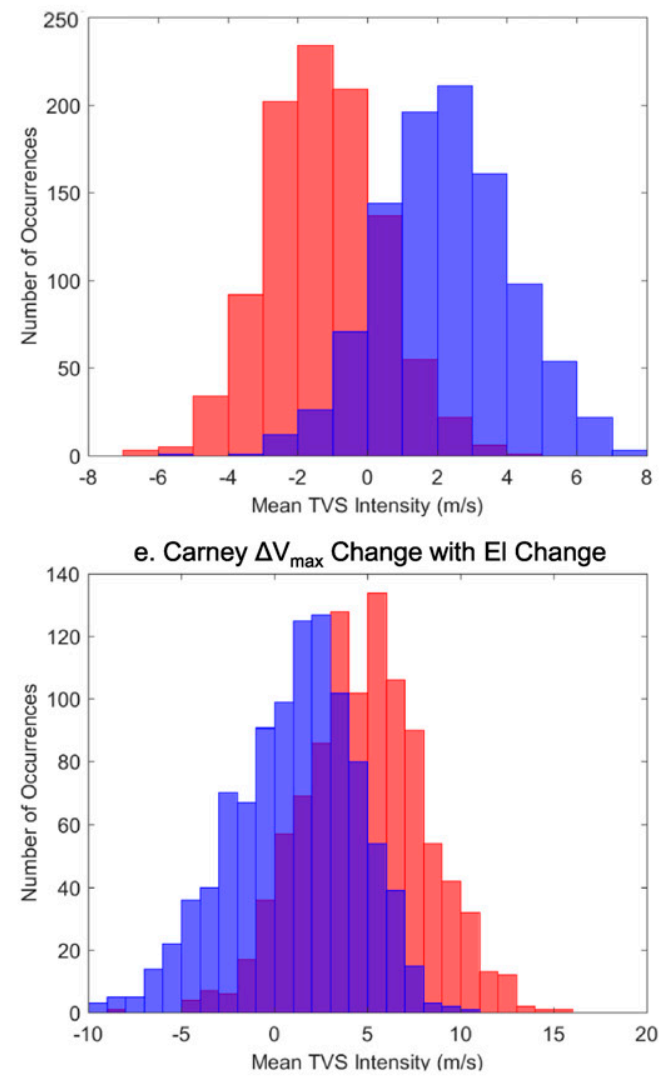

f. All Cases $\Delta \mathrm{V}_{\max }$ Change with El Change

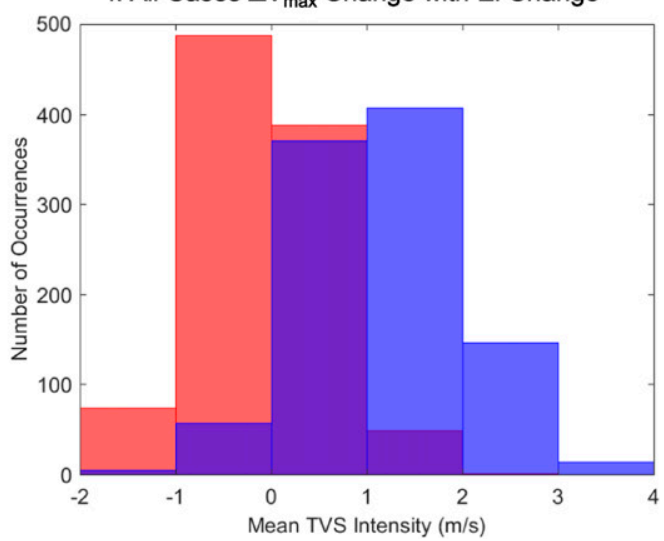

FIG. 8. Histograms of bootstrapped means of changes in $\Delta V_{\max }$ from scan to scan comparing changes associated with increasing topographic elevation from scan 1 to scan 2 (red bars) and decreasing elevation from scan 1 to scan 2 (blue bars). The width of each bar represents a change of $1 \mathrm{~m} \mathrm{~s}^{-1}$. (a) Goshen County case, (b) Lookeba case, (c) El Reno RaXPol case, (d) El Reno MWR case, (e) Edmond-Carney case, and (f) all cases combined.

Additionally, a trimean window was applied to the raw elevation and $\Delta V_{\max }$ data prior to bootstrapping for all cases, with the intent of reducing noise that might be associated with minor changes in elevation from scan to scan, particularly at short time intervals. However, the outcomes of the bootstrapped tests associated with the trimeans did not significantly change the results (not shown).

\section{c. Intensity and surface roughness}

Land-cover types over which the four tornadoes translated are shown in Fig. 9. Roughness lengths for these 


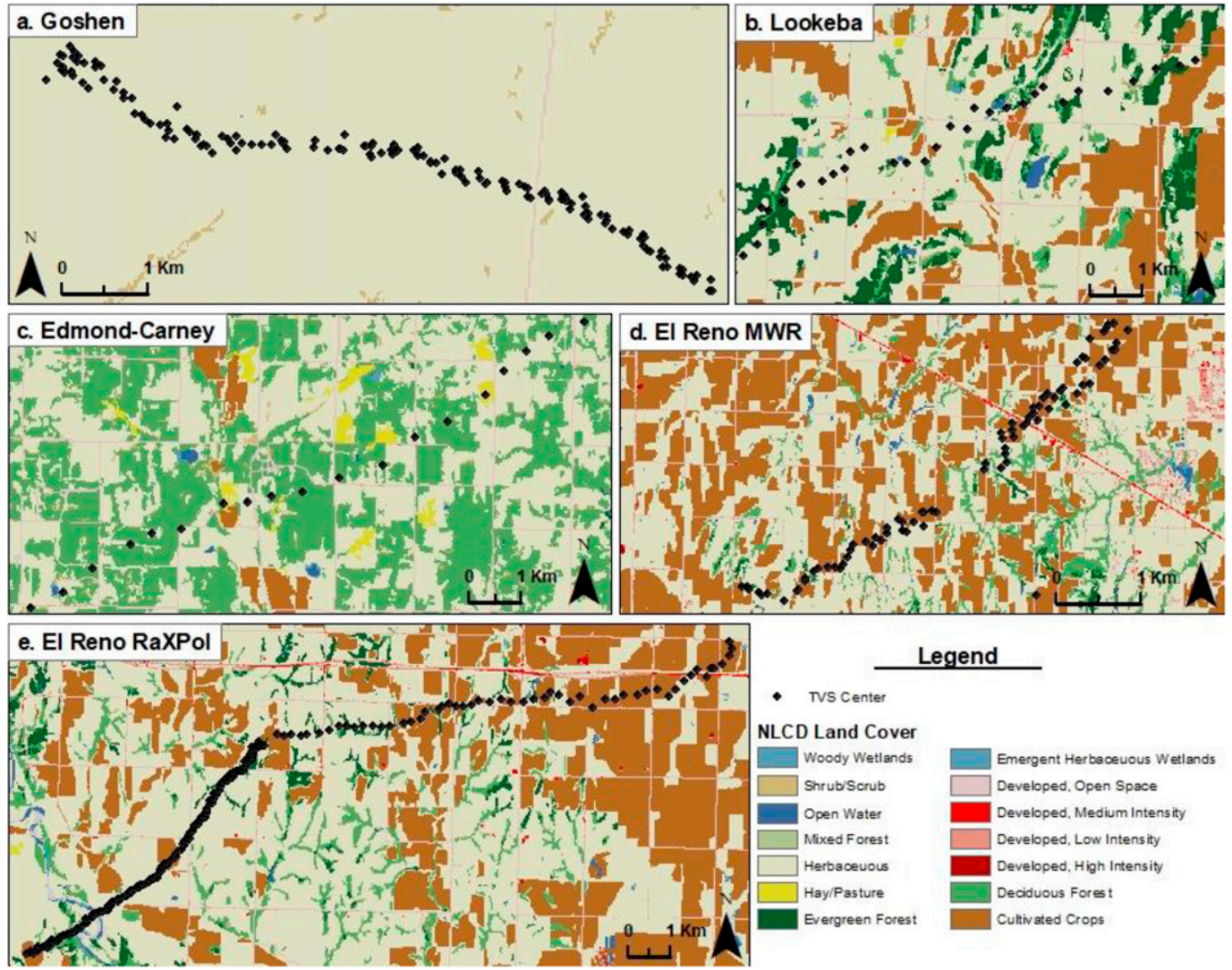

FIG. 9. TVS lat-lon markers (black dots) and NLCD land-cover categories (colors) for each dataset: (a) Goshen County, (b) Lookeba, (c) Edmond-Carney, (d) El Reno (MWR, 2142-2149), and (e) El Reno (RaXPol, 2056-2116 UTC).

various land-cover types range from 0.03 (pasture/hay land cover) to $1.3 \mathrm{~m}$ (evergreen forest-here juniper shrubs-land cover) (Table 2). The Goshen County tornado (Fig. 9a) traveled almost exclusively over grassland/herbaceous land cover. While it is not included for statistical testing here since the impact of friction on the tornado presumably did not vary much, it does provide insight as it can be taken as a control run and will be discussed subsequently in this context. The Lookeba tornado (Fig. 9b) moved over varying land cover including grassland/herbaceous, cultivated crops, mixed forest, deciduous forest, and evergreen forest. Similar land-cover types were observed for the El Reno tornado (Figs. 9c-e). However, there was a trend for less forest and more cultivated crop land with time as the tornado moved generally east-northeast or northeastward. The Edmond-Carney tornado translated over land covers of predominately pasture/grazed fields, grassland/herbaceous land, or deciduous forest.

A time series illustrating the relationship between the average surface roughness (contained within a circle centered on the tornado's center, with a radius of $2 \times R_{\max }$ ) and $\Delta V_{\max }$ is given in Fig. 10. The relationship is rather weak. In the Lookeba case (Fig. 10a), there is some evidence that the tornado was stronger when surface roughness was lower and weaker when surface roughness was higher. In the El Reno RaXPol case (Fig. 10b), there are large peaks and valleys in the surface roughness values that are not well-matched with the patterns in $\Delta V_{\text {max }}$. For the El Reno MWR-05XP case (Fig. 10c), the times when the TVS is strongest occur when surface roughness is generally low. However, there is also a period of time between $\sim 2140$ and 2142 UTC when $\Delta V_{\max }$ was increasing at the same time surface roughness was increasing. In the Edmond-Carney case (Fig. 10d) there is no readily apparent trend between the surface roughness and $\Delta V_{\max }$.

The bootstrapping technique was used to compare the $\Delta V_{\max }$ values for the upper versus lower half of the surface roughness values, and no statistical significance was found (not shown). However, when the technique was employed to isolate the $\Delta V_{\max }$ 's associated with the upper and lower quartile surface roughness data, histograms of the $\Delta V_{\max }$ values associated with these levels 

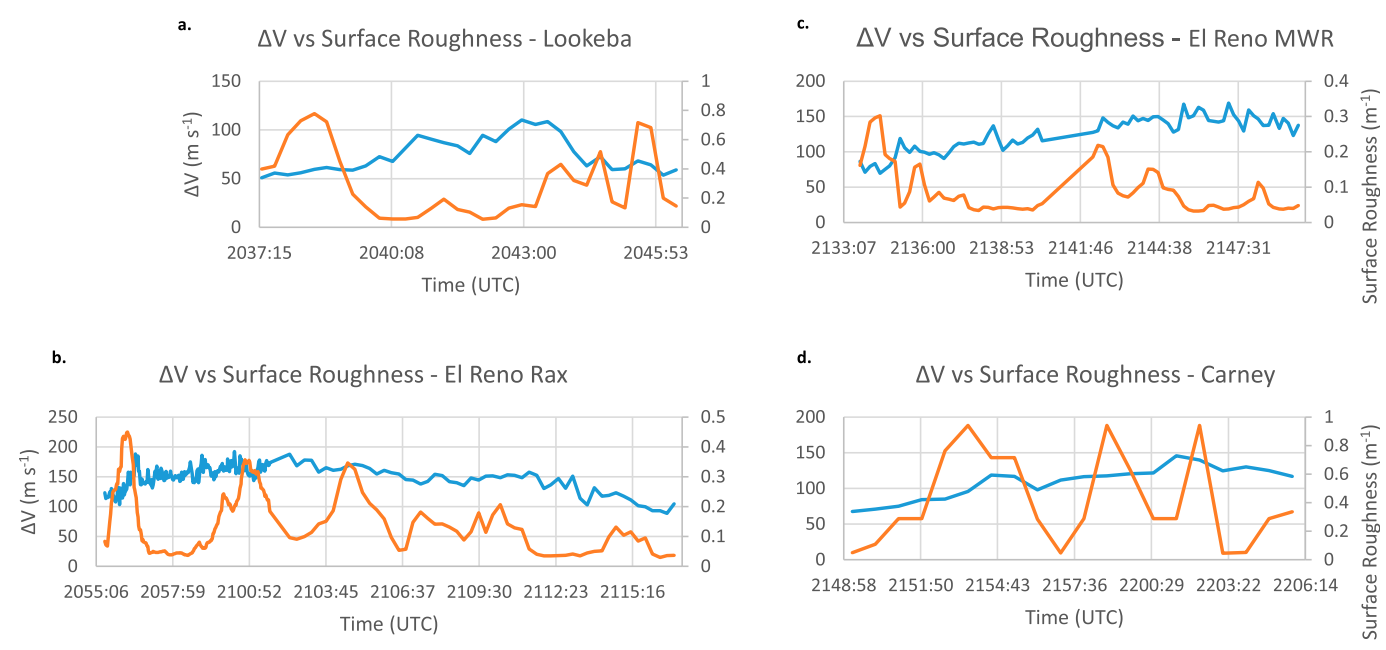

$\Delta \mathrm{V}(\mathrm{TVS})-$ Mean Sfc Rough

FIG. 10. Time series ( $x$ axis) of surface roughness $\left(\mathrm{m}^{-1}\right.$, red line, right $y$ axis) and $\Delta V_{\max }$ observations ( $\mathrm{m} \mathrm{s}^{-1}$, blue line, left $y$ axis) for four cases: (a) Lookeba, (b) El Reno (RaXPol data), (c) El Reno (MWR data), and (d) Edmond-Carney.

of surface roughness supported the general qualitative observances made previously (Fig. 11). In the Lookeba case, there is no overlap between the bootstrapped averaged $\Delta V_{\max }$ values for the upper (green) and lower (purple) quartiles: lower surface roughness levels were associated with stronger $\Delta V_{\max }$ values while higher ones were associated with weaker $\Delta V_{\max }$ s (Fig. 11a). The results for the El Reno MWR-05XP dataset were similar to those for the Lookeba tornado (Fig. 11c). Thus, these tornadoes were stronger when friction was lower. For the El Reno RaXPol case, there was a statistically significant trend of the opposite relationship: stronger (weaker) $\Delta V_{\max }$ values were associated with higher (lower) surface roughness values (Fig. 11b). The Edmond-Carney case had a wide range of $\Delta V_{\max }$ values for both the upper and lower quartile surface roughness data. As such, there was nearly complete overlap in the range of $\Delta V_{\max }$ s between the two bootstrapped resamples, implying that surface roughness had essentially no relationship with the tornado intensity over the timeframe and land cover sampled. Furthermore, the original sample size was quite small ( 26 observations), so the upper and lower quartiles had only 5 contributing data points. The small number of samples and large range in values resulted in wide histograms with discrete gaps between the various combinations of means that could be made with the contributing data.

When considering the results from the various cases together, as well as the evidence presented, again no generalized relationship was found. Although some results were statistically significant, a definitive link between surface roughness and TVS intensity is absent.
The Goshen case can serve as a control run since surface roughness did not vary much. In this case, the tornado intensity still changed on the order of $\sim 40 \mathrm{~m} \mathrm{~s}^{-1}$; thus, processes not associated with surface roughness were responsible for these changes. By extension, even correlations established between TVS intensity and surface roughness for the other cases are questionable. Even though there were statistically significant differences between the two sample groups, causality cannot be established-it is entirely possible that the relationships established were coincidental.

\section{d. Intensity and surface roughness changes}

As was the case when examining changes in topographic elevation, there were no statistically significant results when looking at how $\Delta V_{\max }$ changed with time as the tornadoes encountered changes in land cover (Fig. 12). For both the Lookeba and Edmond-Carney cases, which have the two largest ranges of surface roughness values (Table 1), there was a nonsignificant trend of tornadoes weakening when moving from land covers with higher surface roughness to those with lower surface roughness (blue). Alternatively, these cases imply a strengthening in $\Delta V_{\max }$ when moving from lower surface roughness to higher surface roughness. While this nonsignificant relationship is in agreement with the proposed hypothesis that increasing surface friction will cause a tornado to strengthen by promoting stronger convergence and thus a stronger updraft, which will stretch vorticity and allow rotation to penetrate to a radius closer to the axis of rotation, it is possible that the changes in intensity were not caused by the changes in 

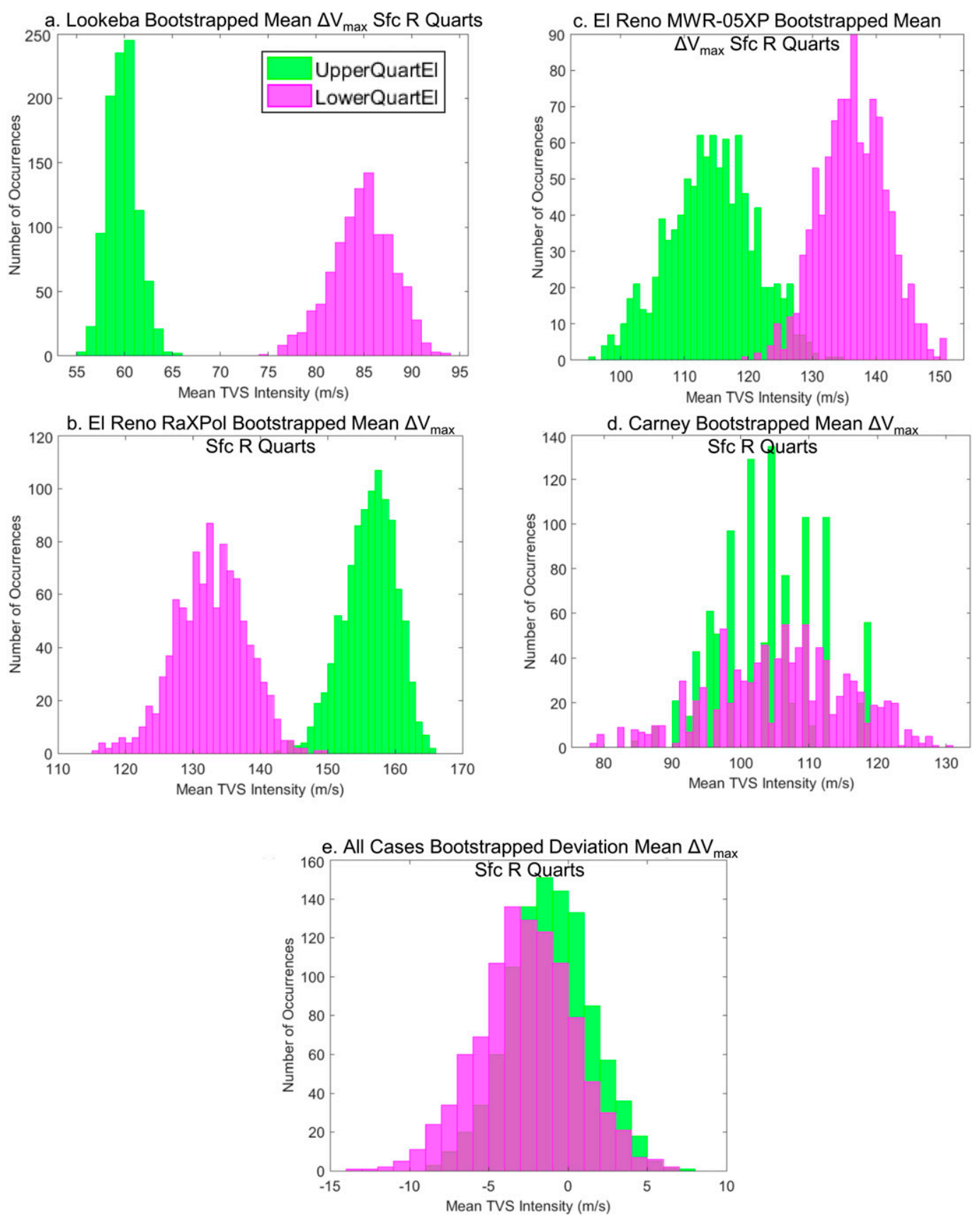

FIG. 11. As in Fig. 7, but for surface roughness. Green = upper quartile (high surface roughness), purple $=$ lower quartile (low surface roughness).

surface roughness. The El Reno MWR-05XP case had a nontrivial trend of the opposite type: the tornado generally strengthened as it moved from higher to lower surface roughness, and weakened moving from lower to higher roughness. As in the elevation change cases, no clear conclusions can be drawn about the relationship between $\Delta V_{\max }$ changes and surface roughness changes for the El Reno RaXPol case. When data from all cases are considered together, the net result is again that there is no generalizable relationship between these variables.

\section{Conclusions and discussion}

In this study, radial velocity data from the MWR-05XP and the RaXPol rapid scan radars were used to compare tornado intensity (via the proxy variable $\Delta V_{\max }$ ) 
a. Lookeba $\Delta \mathrm{V}_{\max }$ Change with Sfc Rough

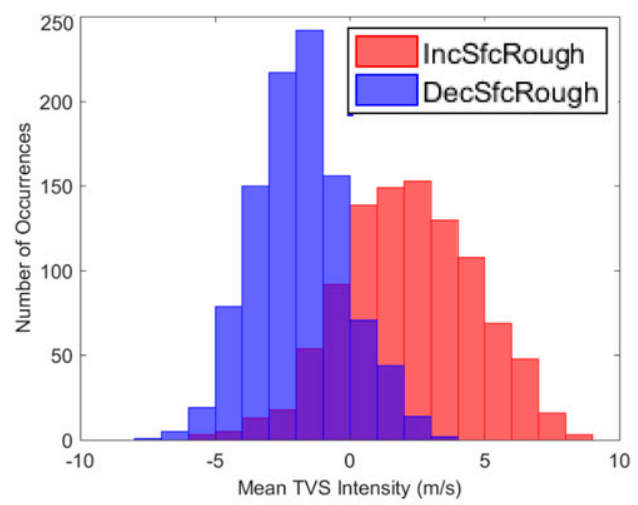

b. El Reno RaXPol $\Delta \mathrm{V}_{\max }$ Change with Sfc

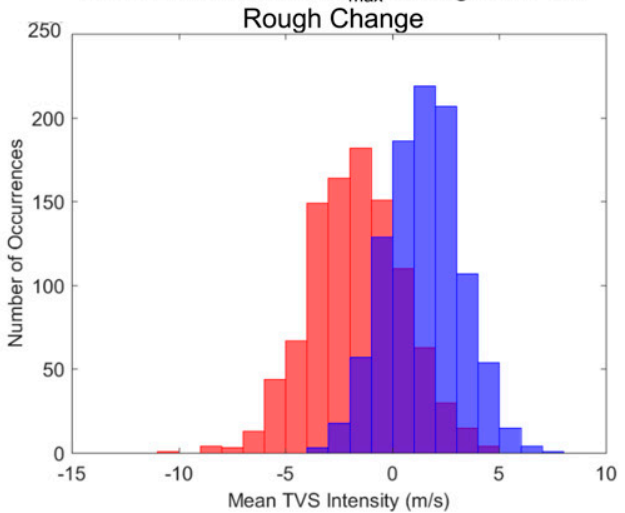

c. El Reno MWR-05XP $\Delta V_{\max }$ Change

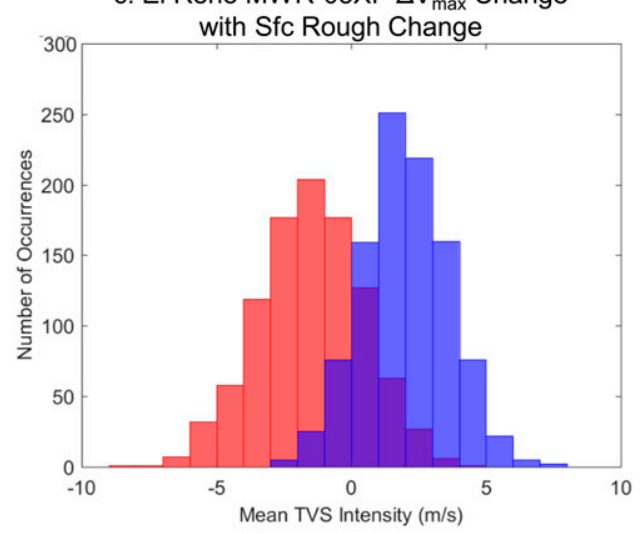

d. Carney $\Delta \mathrm{V}_{\max }$ Change with Sfc Rough Change

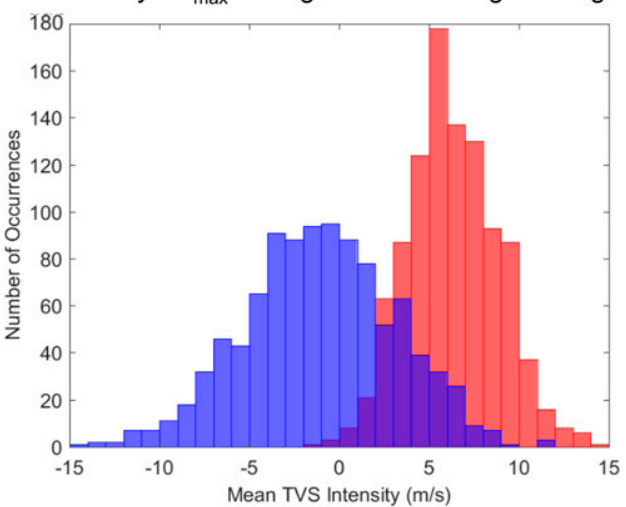

e. All Cases $\Delta \mathrm{V}_{\max }$ Change with $\mathrm{Sfc}$ Rough Change

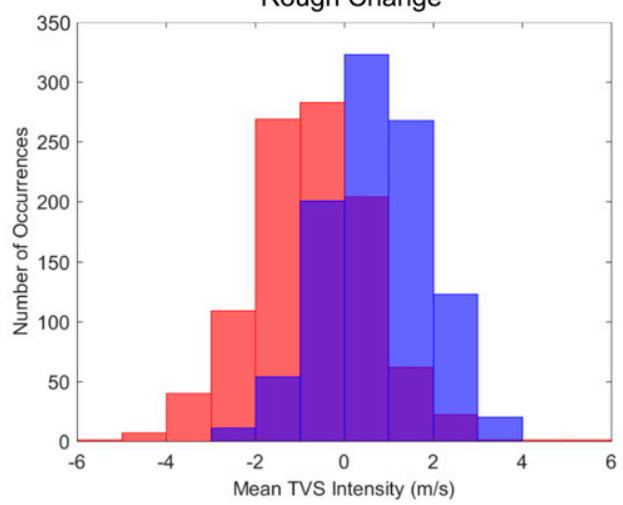

FIG. 12. As in Fig. 8, but for surface roughness. The Goshen County case is not shown because surface roughness was approximately constant (Table 1).

to ground elevation and surface roughness (quantified from an initially categorical land-cover database). The goal was to discern the empirical and statistical relationships between these parameters.

Based on the five datasets (cases) from four tornadoes, it is concluded that for four of the five individual cases, there is a statistically significant relationship between topographic elevation and tornado intensity.
However, the nature of this relationship is different on a case-by-case basis. Two of the five cases had statistically significant differences in bootstrapped means such that lower elevations along the tornado's path were associated with stronger TVSs, while higher elevations were associated with weaker TVSs. Another case was not statistically significant but supported this conclusion generally. For the two other cases, this trend was reversed, yet 
still significant, and when all data were combined together, there is no overall trend. Thus, it is unclear what, if any, relationship truly exists between these variables. When looking at changes in topographic elevation and how they were related to changes in $\Delta V_{\max }$, results were not statistically significant, but different cases again suggested different relationships. Four of the five cases suggested that the TVS strengthened while the tornado descended topographic features, while one case had the opposite trend. When all cases were combined together, there was no statistically significant trend.

The links between surface roughness (a proxy for friction) and $\Delta V_{\max }$ were similarly contradictory, varying from case to case. Two cases had statistically significant results implying that lower surface roughness was correlated with stronger TVSs while higher roughness was correlated with weaker TVSs. In another case, the opposite trend was observed, but it was not statistically significant. The fourth case had no relationship between friction and $\Delta V_{\text {max }}$. When changes in surface roughness were compared to changes in $\Delta V_{\max }$, there were again no statistically significant results, and different cases exhibited different relationships. In two cases, there was an increase in intensity moving from lower to higher surface roughness values, in one case the opposite was observed, and in the fourth case, results were inconclusive.

Most of these cases have statistically significant results, which could support a relationship between either topography or surface roughness and tornado intensity. It is possible to interpret these results in one of two ways. There may indeed be a relationship between topographic elevation or surface roughness and tornado intensity that varies depending upon other factors that were not investigated herein, such as the orientation of the topographic feature versus the approach angle of the storm. This relationship was supported by Lewellen (2014) in his numerical modeling studies. Yet, the lack of consistency between cases with results indicating opposite correlations may mean that these correlations are merely coincidental. It is possible that tornado intensity is impacted by storm-scale processes much more than topography or land cover. Moreover, considering the changes in elevation for these cases were relatively small (30-60 m) in comparison to the depth of the tornado (at least $3 \mathrm{~km}$ ) it is also possible that the terrain here was too low relief to impact the tornado. It is also possible that changes in the intensity of the tornado associated with these factors may only be correlated at heights below what is sampled here. Furthermore, causality could not be tested for any of these relationships.

While this study is the first of its kind to statistically examine trends in tornado intensity in the context of the characteristics of the ground below, there are a number of factors that were not directly considered.
As has already been discussed, we did not look for storm-scale intensification mechanisms nor did we consider how such mechanisms might impact tornado intensity. Furthermore, similar to what Lewellen (2012, 2014) found, there are likely additional complicating factors contributing to the relationships between topography and surface roughness and tornado intensity. Factors that were not considered in this study that may play a role include the angle at which the tornado is ascending or descending the topographic feature, the overall shape of the feature with respect to the inflow air, the "roughness" of the nearby topography, the height of the radar observation, and the diversity of surface roughness/ground cover types within the tornado's core and perhaps the nearby boundary layer flow regime. These factors are included in an ongoing study.

Additionally, it is possible that tornadoes do not behave in a manner consistent with Eq. (1). Since most tornadoes are not bound in the vertical by the tropopause, they may behave more like solid bodies which will merely move up and down as they pass over topographic features. Unfortunately, the vertical extent of the data collected in this study was concentrated at low radar elevation angles and an upper extent of the tornadic circulation was never captured. Furthermore, this study only examined instantaneous changes in tornado intensity. It is possible that there is a lag between when a tornado crosses a topographic or land cover gradient and when the tornado undergoes strengthening or weakening. However, qualitative examination of the trends shown in Figs. 5 and 10 do not indicate any obvious temporal lag in $\Delta V_{\max }$ after a change in elevation or surface roughness.

This study also did not isolate contributions of strengthening from topographic elevation and surface roughness mutually to see which factor was more responsible for the relationships with $\Delta V_{\max }$. Another possible influence of the relationships described herein is the overall strength, size, and structure of the tornado. It is possible that weaker and/or narrower tornadoes may be more susceptible to ground characteristics than stronger and/or wider tornadoes. For example, a relatively small grove of trees may affect a tornado whose width is comparable to the size of the grove, while not affecting a tornado that is much wider than the grove. All tornadoes in this dataset were significant EF2 or stronger tornadoes, thus leaving a void of observations associated with weak tornadoes. Three of the five tornadoes were produced by the same parent storm, which was an exceptionally vigorous supercell, and two of the five cases were of the same tornado, which was a rare, EF5 event and might not provide the best sample data owing to its physical size and intensity. It is likely that a wider 
examination of different storms might provide a more complete picture of the relationships investigated herein.

An ongoing companion study, motivated by the preliminary results presented here will identify storm-scale processes in a larger number of storms in an attempt to isolate periods of intensification that are only associated with changes in topography or changes in surface roughness. This study will also investigate a wider breadth of tornadoes having a variety of widths and strengths, and the impact that the storm motion and approach angle to topographic features might have. Furthermore, the intensity of the TVS with height will be considered to determine if changes in intensity are restricted to lower heights or not, and a principle component analysis will be performed to determine which factors are the most responsible for TVS intensity changes.

Acknowledgments. The authors thank Bob Bluth (Naval Postgraduate School), and Ivan Popstefanija and Bethany Seeger (ProSensing, Inc.) for the use of the MWR-05XP radar and for data processing. We also acknowledge the support from the Advanced Radar Research Center at the University of Oklahoma (including Robert Palmer and John Meier) who maintained and provided improvements to RaXPol. We appreciate the comments and suggestions made by three anonymous reviewers, who helped to refine this work and improve the readability of the manuscript. This work was supported by NSF Awards AGS-1749504 (Houser), AGS-1748177 (French), and AGS-0821231, 1262048, and 1560945 (Bluestein).

\section{APPENDIX A}

\section{Limitations and Assumptions Associated with the Vertical Profile of the Tornado Wind Field}

Owing to the nature of radar-based observational datasets, there are multiple limitations and assumptions that are inherent to the data this study is based upon, and its analysis. The radar cannot collect data precisely at ground level, owing to problems with beam blockage and beam broadening, which results in radial velocity observations being biased by the zero velocities returned from the ground. Furthermore, most of the observations herein are collected above the tornado boundary layer, which is thought to be very shallow, perhaps between 10 and $30 \mathrm{~m}$ (Lewellen et al. 2000; Kosiba and Wurman 2013). This is a fundamental problem with nearly all radar-based studies that cannot reasonably be circumvented. As a result of this sampling limitation, the vertical profile of tornadic winds below $100 \mathrm{~m}$ is unclear; only a handful of observational dataset exist in the peer reviewed literature with velocity measurements collected inside a tornado at multiple heights below $\sim 50 \mathrm{~m}$ (Lee and Wurman 2005; Bluestein et al. 2007; Wurman et al. 2013; Kosiba and Wurman 2013). Therefore, we cannot truly know what the effect of surface roughness or topography is on the wind field at ground level or within the tornado boundary layer, nor can we be completely sure that observations a mere $100 \mathrm{~m}$ AGL are representative of what is occurring at the surface. Consequently, a critical assumption that we make is that these effects are "communicated" upward to the height at which the radar is collecting data several hundred meters AGL. This is likely reasonable for a tornado with a central updraft at low levels, as angular momentum will be advected upward. However, it is less clear what the relationship between winds above the tornado boundary layer and winds at the surface is for a two-cell tornado with an axial downdraft. Furthermore, if the vortex transitions from one-cell to two-cell structure aloft, the vertical profile of winds through this transition becomes unclear. Observational studies of the vertical profiles of tornado vortices have, however, indicated that this assumption does indeed hold in nature for at least some cases (e.g., Bluestein et al. 2007; French et al. 2014; Houser et al. 2015). French et al. (2014) explicitly observed TVS intensity changes that progressed upward over short periods of time. Therefore, we feel reasonably confident that we can infer a relationship between surface conditions and the wind field aloft. Since we are interested in the general intensity of the tornado (i.e., when is it stronger versus weaker), and not the precise wind speeds, it is reasonable to assume the data collected mimic the overall trends of intensity at the ground. However, we cannot rule out that one of the reasons our results are not generalizable might be because the effects of topography and surface roughness are only manifest in the very lowest levels of the vortex, below the heights for which observations are available in this study.

It is understood that the strength of tornadic winds does not remain constant with height (e.g., Bluestein et al. 2007; Rotunno 2013; Kosiba et al. 2013; French et al. 2014; Houser et al. 2015). However, the impact of the surface on the flow traditionally decreases with height. We therefore expect the low-level and nearsurface tornado wind field to be most affected by the presence of terrain and frictional effects. This is why the lowest elevation angle observations were selected for analysis. The effects of surface characteristics are perhaps also seen at higher levels within the tornado, and we assume that any changes in intensity are consistent with height such that trends of intensification or weakening of the winds at the surface are also occurring above the boundary layer. (A subsequent study is currently 
underway to examine if this is indeed true.) However, the authors recognize that this may not always be the case, and the relationship between surface wind and those above boundary layer may be different for different tornadoes and even over the duration of a single tornado.

\section{APPENDIX B}

\section{Limitations Associated with Sampling}

When surveying a tornado over complex terrain, the topography will change below the beam, creating a variation in the height (AGL) of the observation even if nothing else changes. This effect introduces inconsistencies in where the samples are being collected with respect to the physical base of the tornado. However, considering the relatively low relief (a maximum of $\sim 60 \mathrm{~m}$ ) of the features contained within this sample and the fact that the radar likely samples well above the tornado's inflow layer, it is unlikely that this effect will introduce an appreciable source of error to the velocity estimates. Furthermore, since we are investigating how velocities change in response to topography, this is actually a desirable "problem" to have since we can see how the velocity responds at a consistent beam height location as the topography is crossed.

Another issue with beam height arises when the tornado is sampled over a relatively long period of time. The heights of the observations change with range, even if the sampling elevation angle remains constant. During long deployments, as several of the datasets in this study are, the height of the radar beam at the lowest elevation angle changes several hundred meters over the course of the full deployment. Luckily, the topographic features over which the tornadoes traverse are relatively small scale, so the tornado traverses over them rather quickly (on the order of a few minutes). For a hill that is $300 \mathrm{~m}$ wide, a tornado moving at $15 \mathrm{~m} \mathrm{~s}^{-1}$ will cross that feature in $5 \mathrm{~min}$, and the beam height will change at most by $5 \mathrm{~m}$, depending upon the orientation of the hill with respect to the radar location. Over longer time periods, stormscale processes are much more likely to affect tornado intensity than artifacts associated with differences in sampling heights. An objective analysis would somewhat resolve this issue in that we could select a constant height at which to analyze the data. However, we chose to use the raw velocity observations for greater precision over an objectively analyzed reconstruction of the tornadic winds that would have come at the expense of data accuracy. Therefore, while inconsistencies in the physical height of the radial velocity observations will be present over the course of a dataset, the effects of this error source are not likely to significantly affect the statistical results of this study.

Additionally, several other factors introduce error into the radial velocity estimates themselves. The majority of tornadoes in this study are undersampled across the vortex as a result of beam spreading as the distance between the tornado and the radar increases. Aspect ratio correction is not applied here (Wood and Brown 1992), so this issue will negatively bias the magnitude of the velocity estimates (Wood and Brown 1997; Brown and Wood 2012). The effective azimuthal sampling width changes with time as the tornado moves toward and away from the radar. Over the course of a single deployment, the beamwidth can change several hundred meters. This will affect how the tornado is sampled and the resultant velocity estimate. While there will not be much effect when looking at the vortex as it passes over individual topographic features, in the broader context of the entire deployment, there will be some differences in velocity estimates as a result. However, while the negative bias will make the value of the radial velocity estimate decrease, it will also be present for both high and low friction/topography scenarios. Because the distribution of topographic features and land cover types is random over the course of the deployment, it is unlikely that the statistical relationships will change as a result of this bias.

\section{REFERENCES}

Atkins, N. T., K. M. Butler, K. R. Flynn, and R. M. Wakimoto, 2014: An integrated damage, visual, and radar analysis of the 2013 Moore, Oklahoma, EF5 tornado. Bull. Amer. Meteor. Soc., 95, 1549-1561, https://doi.org/10.1175/BAMS-D-14-00033.1.

Bluestein, H. B., 2000: A tornadic supercell over elevated, complex terrain: The Divide, Colorado, storm of 12 July 1996. Mon. Wea. Rev., 128, 795-809, https://doi.org/10.1175/15200493(2000)128<0795:ATSOEC > 2.0.CO;2.

, C. C. Weiss, and A. L. Pazmany, 2003: Mobile Doppler radar observations of a tornado in a supercell near Bassett, Nebraska, on 5 June 1999. Part I: Tornadogenesis. Mon. Wea. Rev., 131, 2954-2967, https://doi.org/10.1175/15200493(2003)131<2954:MDROOA > 2.0.CO;2.

, _ M. M. French, E. Holthaus, R. L. Tanamachi, S. Frasier, and A. L. Pazmany, 2007: The structure of tornadoes near Attica, Kansas, on 12 May 2004: High-resolution, mobile, Doppler radar observations. Mon. Wea. Rev., 135, 475-506, https://doi.org/10.1175/MWR3295.1.

, M. M. French, I. PopStefanija, R. T. Bluth, and J. B. Knorr, 2010: A mobile, phased-array Doppler radar for the study of severe convective storms. Bull. Amer. Meteor. Soc., 91, 579600, https://doi.org/10.1175/2009BAMS2914.1.

_, K. J. Thiem, J. C. Snyder, and J. B. Houser, 2019: Tornadogenesis and early tornado evolution in the El Reno, Oklahoma, supercell on 31 May 2013. Mon. Wea. Rev., 147, 2045-2066, https://doi.org/10.1175/MWR-D-18-0338.1.

Bodine, D. J., M. R. Kumjian, R. D. Palmer, P. L. Heinselman, and A. V. Ryzhkov, 2013: Tornado damage estimation using 
polarimetric radar. Wea. Forecasting, 28, 139-158, https:// doi.org/10.1175/WAF-D-11-00158.1.

_ R. D. Palmer, and G. Zhang, 2014: Dual wavelength polarimetric radar analyses of tornadic debris signatures. J. Appl. Meteor. Climatol., 53, 242-261, https://doi.org/10.1175/JAMCD-13-0189.1.

Bosart, L. F., A. Seimon, K. D. LaPenta, and M. J. Dickinson, 2006: Supercell tornadogenesis over complex terrain: The Great Barrington, Massachusetts, tornado on 29 May 1995. Wea. Forecasting, 21, 897-922, https://doi.org/10.1175/WAF957.1.

Brandes, E. A., 1978: Mesocyclone evolution and tornadogenesis: Some observations. Mon. Wea. Rev., 106, 995-1011, https:// doi.org/10.1175/1520-0493(1978)106<0995:meatso >2.0.co;2.

_ 1984: Vertical vorticity generation and mesocyclone sustenance in tornadic thunderstorms: The observational evidence. Mon. Wea. Rev., 112, 2253-2269, https://doi.org/10.1175/15200493(1984)112<2253:vvgams > 2.0.co;2.

Brown, R. A., and V. T. Wood, 2012: The tornadic vortex signature: An update. Wea. Forecasting, 27, 525-530, https://doi.org/ 10.1175/WAF-D-11-00111.1.

Coffer, B. E., and M. D. Parker, 2017: Simulated supercells in nontornadic and tornadic VORTEX2 environments. Mon. Wea. Rev., 145, 149-180, https://doi.org/10.1175/MWR-D-160226.1.

, — J. M. L. Dahl, L. J. Wicker, and A. J. Clark, 2017: Volatility of tornadogenesis: An ensemble of simulated nontornadic and tornadic supercells in VORTEX2 environments. Mon. Wea. Rev., 145, 4605-4625, https://doi.org/10.1175/ MWR-D-17-0152.1.

Coleman, T., 2010: The effects of topography and friction on mesocyclones and tornadoes. 25th Conf. on Severe Local Storms, Denver, CO, Amer. Meteor. Soc., P8.12, https://ams.confex.com/ ams/25SLS/techprogram/paper_176240.htm.

Dahl, N. A., D. S. Nolan, G. H. Bryan, and R. Rotunno, 2017: Using high-resolution simulations to quantify underestimates of tornado intensity from in situ observations. Mon. Wea. Rev., 145, 1963-1982, https://doi.org/10.1175/MWR-D-16-0346.1.

Davies-Jones, R., 1973: The dependence of core radius on swirl ratio in a tornado simulator. J. Atmos. Sci., 30, 1427-1430, https://doi.org/10.1175/1520-0469(1973)030<1427:TDOCRO> 2.0.CO;2.

- 1986: Tornado dynamics. Thunderstorm Morphology and Dynamics, 2nd ed. University of Oklahoma Press, 197-236.

- 2008: Can a descending rain curtain in a supercell instigate tornadogenesis barotropically? J. Atmos. Sci., 65, 2469-2497, https://doi.org/10.1175/2007JAS2516.1.

- 2015: A review of supercell and tornado dynamics. Atmos. Res., 158-159, 274-291, https://doi.org/10.1016/j.atmosres.2014.04.007.

_ 2017 : Roles of streamwise and transverse partial-vorticity components in steady inviscid isentropic supercell-like flows. J. Atmos. Sci., 74, 3021-3041, https://doi.org/10.1175/JAS-D16-0332.1.

— , R. J. Trapp, and H. B. Bluestein, 2001: Tornadoes and tornadic storms. Severe Convective Storms, Meteor. Monogr., No. 50, 167-222, https://doi.org/10.1175/0065-9401-28.50.167.

Dessens, J. J., 1972: Influence of ground roughness on tornadoes: A laboratory study. J. Appl. Meteor., 11, 72-75, https://doi.org/ 10.1175/1520-0450(1972)011<0072:IOGROT>2.0.CO;2.

Diamond, C. J., and E. M. Wilkins, 1984: Translation effects on simulated tornadoes. J. Atmos. Sci., 41, 2574-2580, https:// doi.org/10.1175/1520-0469(1984)041<2574:TEOST>2.0.CO;2.

Doviak, R. J., and D. Zrnić, 1993: Doppler Radar and Weather Observations. Dover Publications, 562 pp.
Dowell, D. C., and H. B. Bluestein, 1997: The Arcadia, Oklahoma, storm of 17 May 1981: Analysis of a supercell during tornadogenesis. Mon. Wea. Rev., 125, 2562-2582, https://doi.org/ 10.1175/1520-0493(1997)125<2562:TAOSOM>2.0.CO;2.

Dunn, L. B., and S. V. Vasiloff, 2001: Tornadogenesis and operational considerations of the 11 August 1999 Salt Lake City tornado as seen from two different Doppler radars. Wea. Forecasting, 16, 377-398, https://doi.org/10.1175/1520-0434(2001) 016<0377:TAOCOT $>2.0 . \mathrm{CO} ; 2$.

Efron, B., 1982: The Jackknife, the Bootstrap, and Other Resampling Plans. SIAM, $99 \mathrm{pp}$.

, and R. Tibshirani, 1994: An Introduction to the Bootstrap. CRC Press, $456 \mathrm{pp}$.

Elsom, D. M., and G. T. Meaden, 1982: Suppression and dissipation of weak tornadoes in metropolitan areas: A case study of Greater London. Mon. Wea. Rev., 110, 745-756, https://doi.org/10.1175/ 1520-0493(1982) $110<0745$ :SADOWT $>2.0 . C O ; 2$.

EPA, 2008: AERSURFACE user's guide. U.S. Environmental Protection Agency EPA-454/B-08-001, 36 pp.

Evans, J. S., and R. H. Johns, 1996: Significant tornadoes in the Big Horn Mountains of Wyoming. Preprints, 18th Conf. on Severe Local Storms, San Francisco, CA, Amer. Meteor. Soc., 636-640.

Fiedler, B. H., 1994: The thermodynamic speed limit and its violation in axisymmetric numerical simulations of tornado-like vortices. Atmos.-Ocean, 32, 335-359, https://doi.org/10.1080/ 07055900.1994 .9649501$.

_ 2017: Axisymmetric tornado simulations with a semi-slip boundary. Fluids, 2, 9, https://doi.org/10.3390/fluids2040068.

__ , and R. J. Trapp, 1995: Tornado-like vortexgenesis in a simplified numerical model. J. Atmos. Sci., 52, 3757-3778, https://doi.org/10.1175/1520-0469(1995)052<3757:TLVIAS > 2.0.CO;2.

Frazier, A. E., B. L. Hemingway, and J. P. Brasher, 2019: Land surface heterogeneity and tornado occurrence: An analysis of Tornado Alley and Dixie Alley. Geomatics Nat. Hazards Risk, 10, 1475-1492, https://doi.org/10.1080/19475705.2019.1583292.

French, M. M., H. B. Bluestein, I. Popstefanija, C. A. Baldi, and R. T. Bluth, 2013: Reexamining the vertical development of tornadic vortex signatures in supercells. Mon. Wea. Rev., 141, 4576-4601, https://doi.org/10.1175/MWR-D-12-00315.1.

$-,-\longrightarrow,-$, and,- 2014 : Mobile, phased-array, Doppler radar observations of tornadoes at X band. Mon. Wea. Rev., 142, 1010-1036, https://doi.org/10.1175/MWR-D13-00101.1.

— P. S. Skinner, L. J. Wicker, and H. B. Bluestein, 2015: Documenting a rare tornado merger observed in the 24 May 2011 El Reno-Piedmont, Oklahoma, supercell. Mon. Wea. Rev., 143, 3025-3043, https://doi.org/10.1175/MWR-D-14-00349.1.

Fujita, T. T., 1973: Tornadoes around the world. Weatherwise, 26, 56-83, https://doi.org/10.1080/00431672.1973.9931633.

__ 1989: The Teton-Yellowstone tornado of 21 July 1987. Mon. Wea. Rev., 117, 1913-1940, https://doi.org/10.1175/ 1520-0493(1989)117<1913:TTYTOJ>2.0.CO;2.

Golden, J. H., 1968: Waterspouts at lower Matecumbe Key, Florida, September 2, 1967. Weather, 23, 103-115, https:// doi.org/10.1002/j.1477-8696.1968.tb07357.x.

Hardy, R. N., 1971: The Cyprus waterspouts and tornadoes of 22 December 1969. Meteor. Mag., 100, 74-82.

Homar, V., 2003: Tornadoes over complex terrain: An analysis of the 28th August 1999 tornadic event in eastern Spain. Atmos. Res., 67-68, 301-317, https://doi.org/10.1016/S0169-8095(03)00064-4.

Homer, C. G., and Coauthors, 2015: Completion of the 2011 National Land Cover Database for the conterminous 
United States representing a decade of land cover change information. Photogramm. Eng. Remote Sens., 81, 345-354.

Houser, J. L., H. B. Bluestein, and J. C. Snyder, 2015: Rapid-scan, polarimetric, Doppler radar observations of tornadogenesis and tornado dissipation in a tornadic supercell: The "El Reno, Oklahoma" storm of 24 May 2011. Mon. Wea. Rev., 143, 26852710, https://doi.org/10.1175/MWR-D-14-00253.1.

,-- , and -2016 : A finescale radar examination of the tornadic debris signature and weak-echo reflectivity band associated with a large, violent tornado. Mon. Wea. Rev., 144, 4101-4130, https://doi.org/10.1175/MWR-D-15-0408.1.

Houston, A. L., 2017: The possible role of density current dynamics in the generation of low-level vertical vorticity in supercells. J. Atmos. Sci., 74, 3191-3208, https://doi.org/10.1175/JAS-D16-0227.1.

Howells, P. A., R. Rotunno, and R. K. Smith, 1988: A comparative study of atmospheric and laboratory-analogue numerical tornado-vortex models. Quart. J. Roy. Meteor. Soc., 114, 801-822, https://doi.org/10.1002/qj.49711448113.

Hua, Z., and D. R. Chavas, 2019: The empirical dependence of tornadogenesis on elevation roughness: Historical record analysis using Bayes's law in Arkansas. J. Appl. Meteor. Climatol., 58, 401-411, https://doi.org/10.1175/JAMC-D-18-0224.1.

Karstens, C. D., W. A. Gallus Jr., B. D. Lee, and C. A. Finley, 2013: Analysis of tornado-induced tree fall using aerial photography from the Joplin, Missouri, and Tuscaloosa-Birmingham, Alabama, tornadoes of 2011. J. Appl. Meteor. Climatol., 52, 1049-1068, https://doi.org/10.1175/JAMC-D-12-0206.1.

Kellner, O., and D. Niyogi, 2014: Land surface heterogeneity signature in tornado climatology? An illustrative analysis over Indiana, 1950-2012. Earth Interact., 18, https://doi.org/10.1175/ 2013EI000548.1.

Klemp, J. B., and R. Rotunno, 1983: A study of the tornadic region within a supercell thunderstorm. J. Atmos. Sci., 40, 359-377, https://doi.org/10.1175/1520-0469(1983)040<0359:ASOTTR $>$ 2.0.CO;2.

Kosiba, K. A., and J. Wurman, 2013: The three-dimensional structure and evolution of a tornado boundary layer. Wea. Forecasting, 28, 1552-1561, https://doi.org/10.1175/WAF-D13-00070.1.

,-- Y Y. Richardson, P. Markowski, and P. Robinson, 2013: The genesis of the Goshen County, Wyoming, tornado (5 June 2009). Mon. Wea. Rev., 141, 1157-1181, https://doi.org/10.1175/ MWR-D-12-00056.1.

Lamb, H. H., 1957: Tornadoes in England, May 21, 1960. Geophysical Memoirs, No. 99, Meteorological Office, Her Majesty's Stationery Office, $38 \mathrm{pp}$.

LaPenta, K. D., L. F. Bosart, T. J. Galarneau Jr., and M. J. Dickinson, 2005: A multiscale examination of the 31 May 1998 Mechanicville, New York, tornado. Wea. Forecasting, 20, 494516, https://doi.org/10.1175/WAF875.1.

Lee, W., and J. Wurman, 2005: Diagnosed three-dimensional axisymmetric structure of the Mulhall tornado on 3 May 1999. J. Atmos. Sci., 62, 2373-2393, https://doi.org/10.1175/ JAS3489.1.

Lemon, L. R., and C. A. Doswell III, 1979: Severe thunderstorm evolution and mesocyclone structure as related to tornadogenesis. Mon. Wea. Rev., 107, 1184-1197, https://doi.org/ 10.1175/1520-0493(1979)107<1184:STEAMS>2.0.CO;2.

Leslie, F. W., 1977: Surface roughness effects on suction vortex formation: A laboratory simulation. J. Atmos. Sci., 34, 1022-1027, https://doi.org/10.1175/1520-0469(1977)034<1022:SREOSV> 2.0.CO;2.
Leslie, L. M., and R. K. Smith, 1978: The effect of vertical stability on tornadogenesis. J. Atmos. Sci., 35, 1281-1288, https://doi.org/ 10.1175/1520-0469(1978)035<1281:TEOVSO > 2.0.CO;2.

Lewellen, D. C., 2012: Effects of topography on tornado dynamics: A simulation study. 26th Conf. on Severe Local Storms, Nashville, TN, Amer. Meteor. Soc., 4B.1, https://ams.confex.com/ ams/26SLS/webprogram/Paper211460.html.

, 2014: Local roughness effects on tornado dynamics. 27th Conf. on Severe Local Storms, Madison, WI, Amer. Meteor. Soc., 15A.1, https://ams.confex.com/ams/27SLS/webprogram/ Paper254357.html.

, and W. S. Lewellen, 2007: Near-surface vortex intensification through corner flow collapse. J. Atmos. Sci., 64, 2195-2209, https://doi.org/10.1175/JAS3966.1.

_ - — , and J. Xia, 2000: The influence of a local swirl ratio on tornado intensification near the surface. J. Atmos. Sci., 57, 527-544, https://doi.org/10.1175/1520-0469(2000)057<0527: TIOALS $>2.0$. CO; 2 .

Lewellen, W. S., 1976: Theoretical models of the tornado vortex. Proc. Symp. on Tornadoes: Assessment of Knowledge and Implications for Man, Lubbock, TX, Texas Tech. University, 107-143.

1993: Tornado vortex theory. The Tornado: Its Structure, Dynamics, Prediction, and Hazards, Geophys. Monogr., Vol. 79, Amer. Geophys. Union, 19-39.

, D. C. Lewellen, and R. I. Sykes, 1997: Large-eddy simulation of a tornado's interaction with the surface. J. Atmos. Sci., 54, 581-605, https://doi.org/10.1175/1520-0469(1997)054<0581: LESOAT $>2.0 . \mathrm{CO} ; 2$.

Lyza, A. W., and K. Knupp, 2014: An observational analysis of potential terrain influences on tornado behavior. 27th Conf. on Severe Local Storms, Madison, WI, Amer. Meteor. Soc., 11A.1A, https:// ams.confex.com/ams/27SLS/webprogram/Paper255844.html.

$\longrightarrow$, and - 2018: A background investigation of tornado activity across the southern Cumberland plateau terrain system of northeastern Alabama. Mon. Wea. Rev., 146, 4261-4278, https://doi.org/10.1175/MWR-D-18-0300.1.

Markert, A., R. Griffin, K. Knupp, A. Molthan, and T. Coleman, 2019: A spatial pattern analysis of land surface roughness heterogeneity and its relationship to the initiation of weak tornadoes. Earth Interact., 23, https://doi.org/10.1175/EI-D-18-0010.1.

Markowski, P. M., 2016: An idealized numerical simulation investigation of the effects of surface drag on the development of near-surface vertical vorticity in supercell thunderstorms. J. Atmos. Sci., 73, 4349-4385, https://doi.org/10.1175/JAS-D16-0150.1.

— , and Y. P. Richardson, 2014: The influence of environmental low-level shear and cold pools on tornadogenesis: Insights from idealized simulations. J. Atmos. Sci., 71, 243-275, https:// doi.org/10.1175/JAS-D-13-0159.1.

_ J. M. Straka, and E. N. Rasmussen, 2003: Tornadogenesis resulting from the transport of circulation by a downdraft: Idealized numerical simulations. J. Atmos. Sci., 60, 795-823, https://doi.org/10.1175/1520-0469(2003)060<0795:TRFTTO> 2.0.CO;2.

, T. P. Hatlee, and Y. P. Richardson, 2018: Tornadogenesis in the 12 May 2010 supercell thunderstorm intercepted by VORTEX2 near Clinton, Oklahoma. Mon. Wea. Rev., 146, 3623-3650, https://doi.org/10.1175/MWR-D-18-0196.1.

Marquis, J. M., Y. Richardson, P. Markowski, D. Dowell, and J. Wurman, 2012: Tornado maintenance investigated with high-resolution dual-Doppler and EnKF analysis. Mon. Wea. Rev., 140, 3-27, https://doi.org/10.1175/MWR-D-11-00025.1. 
Mashiko, W., 2016: A numerical study of the 6 May 2012 Tsukuba City supercell tornado. Part II: Mechanisms of tornadogenesis. Mon. Wea. Rev., 144, 3077-3098, https://doi.org/10.1175/ MWR-D-15-0122.1.

Naylor, J., and M. S. Gilmore, 2014: Vorticity evolution leading to tornadogenesis and tornadogenesis failure in simulated supercells. J. Atmos. Sci., 71, 1201-1217, https://doi.org/10.1175/ JAS-D-13-0219.1.

Nolan, D. S., and B. F. Farrell, 1999: The structure and dynamics of tornado-like vortices. J. Atmos. Sci., 56, 2908-2936, https:// doi.org/10.1175/1520-0469(1999)056<2908:tsadot>2.0.co;2.

—_, N. A. Dahl, G. H. Bryan, and R. Rotunno, 2017: Tornado vortex structure, intensity, and surface wind gusts in largeeddy simulations with fully developed turbulence. J. Atmos. Sci., 74, 1573-1597, https://doi.org/10.1175/JAS-D-16-0258.1.

Orf, L., 2017: Evolution of a long-track violent tornado within a simulated supercell. Bull. Amer. Meteor. Soc., 98, 45-68, https://doi.org/10.1175/BAMS-D-15-00073.1.

Pazmany, A. L., J. B. Mead, H. B. Bluestein, J. C. Snyder, and J. B. Houser, 2013: A mobile rapid-scanning X-band polarimetric (RaXPol) Doppler radar system. J. Atmos. Oceanic Technol., 30, 1398-1413, https://doi.org/10.1175/JTECH-D-12-00166.1.

Prociv, A. K., 2012: Terrain and landcover effects of the southern Appalachian Mountains on the low-level rotational wind fields of supercell thunderstorms. M.S. thesis, Virginia Tech University, Virginia Tech Electronic Theses and Dissertations, http:// scholar.lib.vt.edu/theses/available/etd-05092012-094035/unrestricted/ Prociv_KA_T_2012.pdf.

Roberts, B., M. Xue, A. D. Schenkman, and D. T. Dawson II, 2016: The role of surface drag in tornadogenesis within an idealized supercell simulation. J. Atmos. Sci., 73, 3371-3395, https:// doi.org/10.1175/JAS-D-15-0332.1.

Rotunno, R., 1979: A study in tornado-like vortex dynamics. J. Atmos. Sci., 36, 140-155, https://doi.org/10.1175/1520-0469(1979) $036<0140$ :ASITLV $>2.0$.CO;2.

_ 2013: The fluid dynamics of tornadoes. Annu. Rev. Fluid Mech., 45, 59-84, https://doi.org/10.1146/annurev-fluid-011212-140639. , and J. B. Klemp, 1985: On the rotation and propagation of simulated supercell thunderstorms. J. Atmos. Sci., 42, 271-292, https://doi.org/10.1175/1520-0469(1985)042<0271:OTRAPO > 2.0.CO;2.

—, G. H. Bryan, D. S. Nolan, and N. A. Dahl, 2016: Axisymmetric tornado simulations at high Reynolds number.J. Atmos. Sci., 73, 3843-3854, https://doi.org/10.1175/JAS-D-16-0038.1.

Schenkman, A. D., M. Xue, and M. Hu, 2014: Tornadogenesis in a high-resolution simulation of the 8 May 2003 Oklahoma City supercell. J. Atmos. Sci., 71, 130-154, https://doi.org/10.1175/ JAS-D-13-073.1.

Smith, R. K., and L. M. Leslie, 1979: A numerical study of tornadogenesis in a rotating thunderstorm. Quart. J. Roy. Meteor. Soc., 105, 107-127, https://doi.org/10.1002/qj.49710544308.

Snider, C. R., 1977: A look at Michigan tornado statistics. Mon. Wea. Rev., 105, 1341-1342, https://doi.org/10.1175/1520-0493(1977) $105<1341$ :ALAMTS $>2.0$.CO;2.
Tang, B., M. Baughan, R. Lazear, K. Corbosiero, L. Bosart, T. Wasula, I. Lee, and K. Lipton, 2016: Topographic and boundary influences on the 22 May 2014 Duanesburg, New York, tornadic supercell. Wea. Forecasting, 31, 107-127, https://doi.org/10.1175/WAF-D-15-0101.1.

Wakimoto, R. M., and Coauthors, 2016: Aerial damage survery of the 2013 El Reno tornado combined with mobile radar data. Mon. Wea. Rev., 144, 1749-1776, https://doi.org/10.1175/ MWR-D-15-0367.1.

— Z. Zeinhoff, H. B. Bluestein, and D. Reif, 2018: The Dodge City tornadoes on 24 May 2016: Damage survey, photogrammetric analysis combined with mobile polarimetric radar data. Mon. Wea. Rev., 146, 3735-3771, https://doi.org/ 10.1175/MWR-D-18-0125.1.

Ward, N. B., 1972: The exploration of certain features of tornado dynamics using a laboratory model. J. Atmos. Sci., 29, 1194-1204, https://doi.org/10.1175/1520-0469(1972)029<1194:TEOCFO > 2.0.CO;2.

Wicker, L. J., and R. B. Wilhelmson, 1995: Simulation and analysis of tornado development and decay within a threedimensional supercell thunderstorm. J. Atmos. Sci., 52, 2675-2703, https://doi.org/10.1175/1520-0469(1995)052<2675: SAAOTD $>2.0 . \mathrm{CO} ; 2$.

Wienhoff, Z. B., 2016: Doppler radar analyses of tornadic supercells on 19 May 2013. M.S. thesis, School of Meteorology, University of Oklahaoma, $163 \mathrm{pp}$.

Wilczak, J. M., D. E. Wolfe, R. J. Zamora, B. Stankov, and T. W. Christian, 1992: Observations of a Colorado tornado. Part I: Mesoscale environment and tornadogenesis. Mon. Wea. Rev., 120, 497-521, https://doi.org/10.1175/1520-0493(1992) $120<0497$ :OOACTP $>2.0$. CO 2 .

Wind Science and Engineering Center, 2004: A recommendation for an Enhanced Fujita Scale. National Weather Service Tech. Memo., Texas Tech University, Lubbock, TX, 95 pp.

Wood, V. T., and R. A. Brown, 1992: Effects of radar proximity on single-Doppler velocity signatures of axisymmetric rotation and divergence. Mon. Wea. Rev., 120, 2798-2807, https://doi.org/ 10.1175/1520-0493(1992)120<2798:EORPOS > 2.0.CO;2.

$\ldots$, and - 1997: Effects of radar sampling on single-Doppler velocity signatures of mesocyclones and tornadoes. Wea. Forecasting, 12, 928-938, https://doi.org/10.1175/1520-0434(1997) 012<0928:EORSOS $>2.0 . \mathrm{CO} ; 2$.

Wurman, J., Y. Richardson, C. Alexander, S. Weygandt, and P. F. Zhang, 2007a: Dual-Doppler and single-Doppler analysis of a tornadic storm undergoing mergers and repeated tornadogenesis. Mon. Wea. Rev., 135, 736-758, https://doi.org/10.1175/ MWR3276.1.

:Dual-Doppler analysis of winds and vorticity budget terms near a tornado. Mon. Wea. Rev., 135, 2392-2405, https://doi.org/10.1175/MWR3404.1. , K. Kosiba, and P. Robinson, 2013: In situ, Doppler radar, and video observations of the interior structure of a tornado and the wind-damage relationship. Bull. Amer. Meteor. Soc., 94, 835-846, https://doi.org/10.1175/BAMS-D-12-00114.1. 